This item was submitted to Loughborough's Research Repository by the author.

Items in Figshare are protected by copyright, with all rights reserved, unless otherwise indicated.

\title{
Reference ontologies to support the development of global production network systems
}

PLEASE CITE THE PUBLISHED VERSION

http://dx.doi.org/10.1016/j.compind.2015.11.002

PUBLISHER

(C) Elsevier

VERSION

AM (Accepted Manuscript)

\section{PUBLISHER STATEMENT}

This work is made available according to the conditions of the Creative Commons Attribution-NonCommercialNoDerivatives 4.0 International (CC BY-NC-ND 4.0) licence. Full details of this licence are available at: https://creativecommons.org/licenses/by-nc-nd/4.0/

\section{LICENCE}

CC BY-NC-ND 4.0

\section{REPOSITORY RECORD}

Palmer, Claire, Esmond N. Urwin, Jose M. Pinazo-Sanchez, Francisco S. Cid, Ester P. Rodriguez, Sonja Pajkovska-Goceva, and R.I.M. Young. 2019. "Reference Ontologies to Support the Development of Global Production Network Systems”. figshare. https://hdl.handle.net/2134/20402. 


\title{
Reference Ontologies to Support the Development of Global Production Network Systems
}

\author{
Claire Palmer ${ }^{1}$, Esmond Neil Urwin ${ }^{1 *}$, Jose Miguel Pinazo-Sánchez ${ }^{2}$, Francisco Sánchez Cid $^{3}$, Ester \\ Palacios Rodríguez ${ }^{3}$, Sonja Pajkovska-Goceva ${ }^{4}$, Robert Ian Marr Young ${ }^{1}$ \\ ${ }^{1}$ Wolfson School of Mechanical and Manufacturing Engineering, Loughborough University, Loughborough, Leicestershire, \\ UK \\ 2 ainia centro tecnológico, Parque tecnológico de Valencia, Avinguda de Benjamin Franklin, 5-11, 46980 Paterna, Valencia, \\ Spain \\ ${ }^{3}$ Instituto Tecnológico de Informática, Camino de Vera s/n, Edif. 8G, Acceso B, CP 46022, Valencia, Spain \\ ${ }^{4}$ Fraunhofer Institute for Production Systems and Design Technology IPK, Pascalstraße 8-9, 10587 Berlin, Germany \\ *Corresponding Author: e.n.urwin@lboro.ac.uk (E. N. Urwin)
}

\begin{abstract}
In competitive and time sensitive market places, organisations are tasked with providing Product Lifecycle Management (PLM) approaches to achieve and maintain competitive advantage, react to change and understand the balance of possible options when making decisions on complex multi-faceted problems, Global Production Networks (GPN) is one such domain in which this applies. When designing and configuring GPN to develop, manufacture and deliver product-service provision, information requirements that affect decision making become more complex. The application of reference ontologies to a domain and its related information requirements can enhance and accelerate the development of new product-service systems with a view towards the seamless interchange of information or interoperability between systems and domains.
\end{abstract}

This paper presents (i) preliminary results for the capture and modelling of end-user information, (ii) an initial higher level reference core ontology for the development of reference ontologies and (iii) the formal logical modelling of Level 1 of the FLEXINET reference ontology using a common logic based approach.

Keywords: product lifecycle management, global production networks, reference ontologies, interoperability, product service systems. 


\section{Reference Ontologies to Support the Development of Global Production Network Systems}

Highlights:

- We present the preliminary results for the capture and modelling of end-user information,

- an initial higher level reference core ontology for the development of reference ontologies,

- the formal logical modelling of Level 1 of the FLEXINET reference ontology using a common logic based approach. 


\title{
Reference Ontologies to Support the Development of Global Production Network Systems
}

\begin{abstract}
In competitive and time sensitive market places, organisations are tasked with providing Product Lifecycle Management (PLM) approaches to achieve and maintain competitive advantage, react to change and understand the balance of possible options when making decisions on complex multi-faceted problems, Global Production Networks (GPN) is one such domain in which this applies. When designing and configuring GPN to develop, manufacture and deliver product-service provision, information requirements that affect decision making become more complex. The application of reference ontologies to a domain and its related information requirements can enhance and accelerate the development of new product-service systems with a view towards the seamless interchange of information or interoperability between systems and domains.
\end{abstract}

This paper presents (i) preliminary results for the capture and modelling of end-user information, (ii) an initial higher level reference core ontology for the development of reference ontologies and (iii) the formal logical modelling of Level 1 of the FLEXINET reference ontology using a common logic based approach.

Keywords: product lifecycle management, global production networks, reference ontologies, interoperability, product service systems.

\section{Introduction}

The nature of competition dictates rivalry and in the domain of manufacturing industry the act of competing for supremacy in the design, production and selling of products. The 21 st century information age is forcing manufacturers to act differently to compete successfully and find different ways in which to not only source and manufacture products but also configure and then sell them to customers.

The servitisation of products i.e. 'the increased offering of fuller market packages or 'bundles' of customer focused combinations of goods, services, support, self-service and knowledge' [1] is proving to be an enticing form of selling products via services to customers. Whilst the benefits can be seemingly apparent and instant, the actuality is that there are many additional components that are necessary.

The challenge for manufacturing industry which is servitising products is, what is the most effective way to design, produce and sell a product together with it associated service components effectively, to form a Product-Service System (PSS)? At the heart of this is how to align and integrate a traditional product lifecycle viewpoint with a more modern service lifecycle to develop a PSS. Additional complexity is added to this approach when Global Production Networks (GPN) are to be configured and reconfigured and in the face of rapidly changing product-service requirements. By employing a GPN, organisations can adopt technology at a faster pace, lower costs and be more open to change $[1,2]$. But an important aspect must be considered carefully, that of information interoperability between suppliers, manufacturers and service provision mechanisms. This becomes paramount when configuring sizeable and diverse GPN across potentially large geographical areas and between widely varying domains and contexts. It can introduce a wide and varied range of risks and perturbations from diverse system processes and capabilities, to different legislation and laws. One such method that can mitigate these risks to information interoperability is the use and application of ontological reference models.

What can be derived from this is that organisations are tasked with providing product lifecycle management (PLM) approaches and solutions to enable the sharing, use and reuse of information and knowledge, the main objective of this being to achieve and maintain competitive advantage for their Product-Service Systems [3]. They must be able to react to change and understand the balance of possible options when making decisions on complex multi-faceted problems, GPN is one such domain in which this applies.

There are a number of interesting formal ontologies that have been developed. The first is the Interoperable Manufacturing Knowledge Systems (IMKS) project, a UK EPSRC funded project, demonstrated the potential of reference ontologies for interoperable manufacturing knowledge sharing [4] across a range of company groups operating within and across product life cycle phases. These groups may work across multiple organisations and make use of a variety of software systems. The IMKS project explored the concept of a reference ontology to afford an effective basis for concept specialisation across a range of manufacturing systems within an individual enterprise. As part of this it developed a set of core concepts to specifically enable the sharing of knowledge across design and production domains. Design and production concepts were specialised from generic foundation 
ontology concepts in order to provide the required level of interoperability [5].

The IMKS project exploited a Common Logicbased ontology language to express the core concepts. In order to avoid subjective interpretation and to model relationships consistently between concepts, the underlying semantics upon which the concepts are based need to be formalised. Chungoora et al. [6] justified the use of Common Logic to capture manufacturing concepts, discovering that in order to model complex manufacturing domains the capabilities of Common Logic are preferable to the less expressive capability of the Web Ontology Language (OWL). The use of Common Logic also enables the utilisation of the Process Specification Language (PSL) [7], as PSL is written in the Common Logic Interchange Format (CLIF) [8]. PSL provides formal process reasoning enabling the capture of generic manufacturing process semantics.

Imran [9] extended the IMKS concept to consider the use of formal Common Logic-based ontologies to support knowledge sharing within the assembly domain. Imran [9] proposed a framework of key reference concepts specialised from a generic foundation supporting the creation of interoperable application specific ontologies.

Hastilow [10] has also progressed the work of the IMKS project, employing a Common Logicbased approach applied to systems interoperability. Hastilow [10] used a core concept ontology to describe manufacturing systems, extending the ontology coverage across the product lifecycle and considering interoperation between defined systems. Hastilow [10] developed a Manufacturing Systems ontology applicable to any Manufacturing Systems domain.

Two European Framework Programme 7 (FP7) projects have produced work that is aligned with the domain in question, those being the Manufacturing Service EcoSystem (MSEE) [11] FP7 project and the POP* methodology created by the Athena FP7 project [12]. The Manufacturing Service EcoSystem (MSEE) FP7 project aims to produce "new Virtual Factory Industrial Models where service orientation and collaborative innovation will support a new renaissance of Europe in the global manufacturing context" [11]. MSEE considers the hierarchical modelling of tangible and intangible manufacturing assets. MSEE utilises formal semantics but is based on OWL Description Logic so, whilst it provides an effective framework from which to draw manufacturing concepts, FLEXINET is able to extend MSEE capabilities through the more expressive manufacturing business modelling provided by Common Logic.

The POP* [12] methodology aimed to develop ways of capturing the design and management issues which occur during enterprise collaboration. The POP* (Process, Organisation, Product and others) language provides a set of concepts to support model exchange between collaborating enterprises. POP* consists of five dimensions: Process, Organisation, Product, Decision and Infrastructure. The POP* objective was to provide a mapping methodology from several enterprise modelling languages to the POP* format. The aim of this was to enable interoperability between collaborating enterprises using different modelling languages. The POP* language utilises the object-role-action paradigm. According to this approach, there are two basic domains in an enterprise: object domain (both physical and information objects) and action domain (such as activity, process, tasks, operations, etc.). The concept of role enables these two domains to be related. Indeed, various objects play different roles in different actions (for example, objects plays roles as input, output, resource and control in a process) [12].

The Integrated Supply Network Ontology (iSNO) is related work, developed to support the visualisation and navigation through multidimensional supply networks initiated during the amerigo project [13]. The objective of iSNO was to develop a platform for gathering and maintaining the information for visualising and analyses of Supply Networks, in a form of a Strategic Supply Network Map. The iSNO - Strategic Supply Network Map should support the requirements for providing a holistic view of the supply network, distributive modelling and modification, integrating information from different sources.

Relative to the development of reference ontologies for GPN, two international standards are significant, the first is the afore mentioned ISO 18629:2004, Industrial automation systems and integration, Process Specification Language [7]. This standard provides intuitions for reasoning about various forms of processes and thus forms an effective foundation for capturing process-related meaning [4]. The intent of the PSL Core is to provide a set of intuitive primitives adequate for describing the fundamentals of manufacturing processes, defined as formal axioms. The second applicable standard is ISO 10303-239:2012 [14] which, concerns Product LifeCycle Support (PLCS), specifies the information required to support a product throughout its life [14] and a structure for information exchange. This PLCS standard supports feedback of information acquired during product usage, including feedback on product usage, support activities and resources used to provide support. PLCS contains an activity model defined in the IDEF0 modelling language [15] and an information model written in the Express information modelling language [15]. The activity mod- 
el describes an application in terms of its processes and information flows. The information model has three key concepts (product, activity and resource) each of which may be associated with properties, states or locations. PLCS makes the important distinction between planned products (i.e. those still at the design stage) and realised products (i.e. those in use).

Another aspect aligned to standards that is relevant is the Core Product Model from the National Institution of Standards and Technology (NIST) [16], it captures product model data over the lifecycle of the product. The product is modelled in terms of three concepts: function (what the product is supposed to do), form (in terms of geometry and material) and behaviour (how a form implements its function) and is represented in UML. The Core Product Model defines core manufacturing concepts such as Feature, Form and FormFeature.

A number of systems modelling approaches have standardised concept models that are relevant and of importance. The Systems Engineering Conceptual Model was developed by members from the International Council on Systems Engineering (INCOSE), the AP233 committee, and SysML development group and represents a consensus on the definition of some of the key system modelling concepts $[17,18]$. The Systems Engineering Conceptual Model is expressed as a UML class diagram and captures essential concepts of systems engineering such as System, Requirement, Stakeholder, Behaviour and Environment [19]. The Systems Engineering Conceptual Model was used as input to requirements for SysML. SysML is a general purpose modelling language intended to model systems from a broad range of industrial domains. SysML is graphical language which extends UML and provides a foundation for representing the requirements, behaviour, structure and properties of a system. AP233 is an information exchange model for the exchange of data between Systems Engineering, Systems Architecture Description and related tools. It could be used to exchange information between a SysML and another Systems Engineering application. AP233 is based on the Express modelling language [20] and is a product-centric information model containing concepts of Product, Product Version and Product View Definitions [18]

The Object Process Methodology (OPM) [21] unifies function, structure and behaviour within a single model. OPM is a graphical representation language which considers the interactions between entities and the processes which act upon them. It can be translated into natural language (Object Process Language (OPL)) and RDF [22]. OPM is better able to model processes and interaction between systems than SysML.
The premise of this paper is to put forward the notion that the application of formal reference ontologies to a domain and its related information requirements so as to enhance and accelerate the development of new PSS with a view towards the seamless interchange of information or interoperability between systems and domains. This approach is being developed as part of the research being undertaken in the EU FP7 FLEXINET project.

This paper is structured as follows. Section 2 discusses the FLEXINET project and its purpose. Section 3 sets out the methodological approach and development of reference ontologies for productservice systems. Section 4 looks at the application of the FLEXINET reference ontology. Section 5 puts forward a discussion of the aspects addressed in this paper and Section 6 draws the paper to a close with conclusions and further work.

\section{The FLEXINET View}

FLEXINET aims to support decision-making in the early design of global production network configurations based on the implementation of new complex technologies. FLEXINET will apply advanced solution techniques to the provision of a set of Intelligent Production Network Configuration Services that can support the design of high quality manufacturing networks, understanding the costs and risks involved in network re-configuration, and then mitigating the impact of system incompatibilities as networks change over time. These are fundamental requirements for high quality decisionmaking in the early design of intelligent manufacturing system networks. These innovative concepts will enable a fast and efficient response to market variations and be easily adaptable across industrial sectors. The FLEXINET concept is illustrated in Figure 1.

FLEXINET takes the view that new manufacturing business modelling methods are needed that can model business cases and identify the critical network relations that underlie the business operation. Such methods and models are essential to the ability to define both the production network knowledge that must be captured and the queries that must be made if new business configuration possibilities are to be evaluated. Product servitisation adds to the complexity of this problem as the relationships between product lifecycles and service lifecycles also need to be understood and their impact on production system networks specified within the resulting business models.

The main aims of the FLEXINET ontological research are the following, (i) document key semantic concepts, knowledge constraints and interrelationships in the context of globalised produc- 
tion networks, (ii) structure and formally model concepts, relationships, constraints and related facts to provide an underpinning environment against which specific network configuration designs can be evaluated and (iii) develop methods for ontology querying from which to evaluate the compliance of potential production network configurations from both OEM and SME perspectives. In essence, the general approach of the FLEXINET project is to provide a common foundation of ontologies and knowledge bases to support reconfigurable software services and applications, as depicted in Figure 2 .

\section{$<$ Figure 1 here>}

Figure 1. The FLEXINET Concept: Intelligent Production Network Configuration Services.

$<$ Figure 2 here>

Figure 2. The FLEXINET approach to supporting software services with ontologies and knowledge bases.

\section{A Reference Ontology for Product- Service Systems}

There have been two starting points for the development of the FLEXINET formal reference ontology for product-service systems. The first has been three industrial case studies which have provided a solid base for the elicitation and capture of information and knowledge, they concern three distinct areas of manufacturing, those being pumps and valves, whites goods and food and drink. The importance of the requirements capture process detailed below has been to explore the level of commonality that can be identified from these three manufacturing business areas. From these use cases a set of end user requirements have been elicited to help focus the approach of the FLEXINET project research. These end user requirements relate mostly to specific processes of the end users. They address expectations identified during a number of semistructured interviews with the industrial end users. Four iterative requirements engineering processes were used to derive concise, applicable, correct and complete requirement statements, these were (i) analyse requirements for scope and applicability (ii) validate the requirement statements (iii) classify and organise requirements for each end user (iv) prioritise requirements relative to FLEXINET project objectives. It has been essential to prioritise these so that the most important requirements could be focused upon relating to global manufacturing networks and the establishment of new product- service businesses. Each end user was asked to rank their set of requirements using a scale of one to three, where the value of one was very important, the value of two was of medium importance and the value of three was of least important. Once this had been accomplished, the project then assessed those sets of end user requirements to derive a core set of fundamental project requirements. In the context the FLEXINET end users there are three main business requirements that the reference ontology must support. These are (i) the rapid response to customer new business requirements, (ii) the potential business opportunities derived from the move towards product-service based business models and (iii) the potential business opportunities arising from the exploitation of new technologies.

The second starting point has been the assessment of existing ontological research work, this being work from the Interoperable Manufacturing Knowledge Systems (IMKS) [6] project, the Manufacturing Service Ecosystem (MSEE) project [11] and the Manufacturing Information ontological model set out by Hastilow [10], they have been assessed for applicability to the GPN and PSS domains.

From the analysis of this wide ranging set of requirements a set of core areas for the development of reference ontology has been identified as illustrated in Figure 3. In order to meet those business requirements it is fundamental to develop a reference ontology that can represent a network composed of systems and thus with specialisation a global production network. One important aspect of this is to be able to model and represent inputs and outputs between those systems within a network.

\section{$<$ Figure 3 here $>$}

Figure 3. The supporting formal ontologies and knowledge bases.

The FLEXINET approach focuses on the intelligent configuration of a network of products or product-service systems, to support interoperability between systems and domains the approach utilises a core foundation ontology. Figure 3 provides a diagram showing the benefits of such an approach, the intent being to develop domain specific ontologies from a common core or reference ontology. The benefit of such a method is that by developing systems from a common foundation, it enables easier communication between different types of systems and in this context, across different production networks. 


\subsection{General Ontology Structure}

To enable ease of construction and to facilitate re-use across domains the FLEXINET ontology is organised into five levels, as illustrated in Figure 4. Each level inherits concepts from and provides additional concepts to the level above, the ontology becoming more domain specific with each level. Five levels are needed to specialise the concepts from the foundation to the specific domains. Figure 4 shows example domains at each level, the scope of FLEXINET being indicated in red.

<Figure 4 here>

\section{Figure 4. The FLEXINET ontology levels}

Level 0 Core consists of foundation concepts applicable to all domains, having nothing to do directly with Product-Service Lifecycle Systems. The foundation concepts include time, events, aggregation and lists and are derived from the Highfleet Upper Level Ontology (ULO) [23]. Level 1 contains the few key concepts necessary to model any system. A system transforms inputs into outputs and is defined as "a combination of interacting elements organized to achieve one or more stated purposes" [24]. Level 2 uses Banathy's classification [25] to specialise systems into "Natural Systems" and "Designed Systems". Natural systems are living systems of all kinds, the solar system and the Universe. Designed systems are man-made creations, including fabricated physical systems, conceptual knowledge and purposeful creations. FLEXINET will provide decision support for product lifecycle management and, as this requires human input (i.e. input from a living system), the scope of FLEXINET covers purposeful creations and overlaps into natural systems.

Level 3 further differentiates designed systems, FLEXINET being concerned with Manufacturing Business Systems which are specialised within Level 4. At this level FLEXINET considers Product-Service Lifecycle Systems, implemented as Global Production Networks. The lifecycle phases are denoted as design, produce, operate and end of life (including disposal, recycling and remanufacturing). The focus of FLEXINET is how to design a GPN to produce and operate a product-service. The main area FLEXINET considers within the Product-Service Lifecycle is "Produce" (producing the product) but the scope also overlaps into "Design" (of the network) and "Operate" as the operation of the product and the service needs to be considered. Level 5 applies Level 4 to case studies creating enterprise specific domains.

\subsection{Reference Ontology Level 1 Concepts and Relations}

Figure 5 sets out the level 1 ontology. It applies the Unified Modelling Language (UML) [17] technique to describe the details about the concepts and relations necessary to specify a system. This ontology level utilises the concept TimeSpan (inherited from Level 0) and contains two parent concepts: Basic and Role. A TimeSpan includes the first and last instants of a date and all the instances in between [23]. A Basic concept [26] is independent of the system or context, its definition does not depend on another concept and an instance of a Basic always retains its identity as such. Examples of Basic are information and material. A Basic can be comprised of Basics, e.g. "bottled water" is comprised of the materials "bottle", "cap" and "mineral water". A System is subtype of Basic and provides a context for the Roles it contains (shown via the "depends on" relation and the composition filled diamond in Figure 5).

The definition of a Role depends on a context, an instance of a Role cannot exist without a context and the playsRole relation is transitory. For example, within Company $\mathrm{X}$ a drying machine has a Role as a product (context 'production system'), which Company Y might buy to use as a resource (context 'drying system'), hence the drying machine has changed Roles, whereas the Basic "drying machine" is always a "drying machine".

It can be seen that a drying resource Role cannot exist without the drying system context, if Company $\mathrm{Y}$ closes down the drying system, the drying resource role ceases to exist. Roles may be comprised of Roles (e.g. a manufacturing Role may require design and production Roles).

$<$ Figure 5 here >

Figure 5. FLEXINET Level 1 Systems Ontology

A Basic plays a Role for certain TimeSpans, modelled in the ternary relation "playsRole". For example in the context of a manufacturing organization system, the Basic "bottled water" can play the Role of a Product during the TimeSpan of the system. Within Company $\mathrm{Y}$ a drying machine could play the Role of a drying resource for a TimeSpan of five years, placed into storage for a TimeSpan and then play the Role of a drying resource again for a further TimeSpan.

A Basic can play more than one Role at the same time. A Role can be played by more than one Basic, e.g. the role of a laundry would require a washer and a drier. There is no requirement for a Basic to play a Role (shown by the $0 .{ }^{*}$ multiplicity next to the Role concept in Figure 5). Role and 
Basic concepts exist separately and have separate identities. There is also no requirement for a Role to be played by a Basic, enabling empty Roles to be modelled (e.g. if a drying machine playing the Role of a drying resource broke down, the need for the drying resource would still exist).

A Basic may affect the state of a role, e.g. the size of a Basic "bottled water" playing the Role of a product could influence the dimensions required for a packing resource Role. Additionally a Role may affect the state of a Role, e.g. within the lecturer Role more duties allotted to the administration Role would cause duties to be removed from the teaching Role).

Scenario concepts are defined within the FLEXINET reference ontology in order to provide a method to describe multiple alternative instantiations of global production networks. Additionally scenarios can be composed of scenarios.

The four key Roles which describe a system are input, output, resource and control. An input represents what is brought into and is transformed or consumed by the system to produce outputs. An output represents what is brought out from or is produced by the system. A resource is used by or supports the execution of the system. A control is a condition required to produce correct system output $[12,15]$.

The FLEXINET ontological approach is applying the Knowledge Framework Language (KFL) this is a heavyweight ontology language based upon Common Logic [8]. This KFL code represents the formal ontology code that will be used to support FLEXINET services and applications. This approach is being applied due to its improved expressiveness as put forward by Chungoora et al. [6].

$<$ Figure 6 here >

Figure 6. Level 1 context in KFL

For each reference ontology level within the KFL code a context must be stated so as to uniquely identify the concepts relative to a given perspective, in this instant the perspective is level 1. Figure 6 shows the KFL code for the Level context statement. The first line states 'Use MLO', this is the Highfleet Middle Level Ontology (MLO). The purpose of this is a reference point to a general top level ontological lexical resource to be used by the FLEXINET reference ontology. Such an ontology contains concepts useful to many perspectives. The second line 'Ctx 1SYSCtx' defines the context (Ctx) as the FLEXINET Level 1 Systems (SYS) Context (1SYSCTx). The third line 'Inst UserContext', identifies that 1SYSCTx is an Instance (Inst) of UserContext. UserContext is a MLO concept, not to be mistaken with Level 5 End User contexts. The final line states that it inherits from the MLO, i.e. includes the concepts from the MLO, in addition to the user defined concepts.

$<$ Figure 7 here>

Figure 7. Level 1 property KFL for 'basic'

Properties are frames that allow concepts to be defined. Figure 7 illustrates the property 'Basic' (Prop Basic) from the level 1 UML diagram in Figure 5. It is an instance of a type (Inst Type), as such a type is something that always exists and additionally it is an instance of a non-logical functor (Inst NonLogicalFunctor) and hence is infinitely valued. It has a super-property (sup) of a Particular (things that are unique) contained within the Highfleet MLO. 'PartitionedBy' states that the only sub-properties of Basic can only be 'System', 'Energy', 'Material' and 'Information' (as per the UML diagram in Figure 5), additionally 'PartitionedBy' implies that any instances of basic subproperties are pairwise disjoint, i.e. an instance of a sub-property cannot be an instance of another subproperty, for example Gas_ID_27 cannot be an instance of Energy and Material. The final part of the KFL code is a 'rem' statement. These are textual statements within the code not meant for computation, providing more information for user comprehension of the specific items of KFL code. For property 'Basic' the rem statement defines what a Basic is and its sub-properties. '/sym' is a hyperlink to other items or relations within the ontology.

$<$ Figure 8 here>

Figure 8. Level 1 property KFL for 'role'

Figure 8 sets out the Role property and the associates relationships, those of 'affectsState' and 'roleContainsRole'. The property Role is an instance of a Type and has a super-property (sup) of MLO.AbstractEntity (i.e. does not have the relationships MLO.LocatedIn). It is 'disjointWith' a Basic, i.e. an instance of role cannot also be an instance of a basic. The rem statement explains meaning of the property Role, in this instance, all roles include AbstractEntities that participates in systems, that a role cannot exist without a context, that all Roles are pairwise disjoint and as per the UML representation a Basic can play more than one Role.

The relationship 'affectsState' (shown in Figure 8 ) is an instance of a binary relationship between two properties with a rigid relationship ('RigidRel') i.e. these relationships will only hold over a particular timespan. It is an instance of a asymmetric 
binary relationship. 'Sig' states the properties of the arguments of the relationship i.e. in this case the relation must be between a particular and a role. 'Args' are strings that provide more detailed descriptions of argument properties. 'lex' is a string template intended to provide a human-readable expression of its semantics. The relationship of 'roleContainsRole' is also an instance of a binary and rigid relationship but, is an instance of an antisymmetric binary relationship. These two relationships enable roles to be composed of roles and for those roles to be differentiated.

<Figure 9 here>

Figure 9. Level $1 \mathrm{KFL}$ code for a scenario

A new concept addition at level 1 is the concept, or "property" in KFL terminology, of Scenario (see Figure 9). Scenario concepts are defined within the FLEXINET reference ontology in order to provide a method to describe multiple alternative instantiations of global production networks. It is defined at level 1 in order to catch its relationships with Basics and Roles.

\section{$<$ Figure 10 here $>$} sRole'

Figure 10. Level 1 relationship KFL for 'play-

Figure 10 depicts the KFL code for, the PlaysRole relationship. It is an instance of a ternary relationship ('Inst TernaryRel') between three properties and a non-rigid relationship ('NonRigidRel'), i.e. these relationships will only hold over a particular timespan. 'Sig Basic Role Scenario' states the properties of the arguments of the relationship i.e. in this case the relation must be between a basic, a role and a scenario.

It is noteworthy that while the UML model shows a quaternary relation, ECLIF provides an operator "HoldsIn" which provides the equivalent of the "timespan" shown in Figure 5.

Utilising this relationship and the three concepts of Basic, Role and Scenario we can start to model useful GPN relationships. Consider two possible apple suppliers to a drinks manufacturer, those of BrownFarms and JonesFarms. These are two instances of basic that play the role of suppliers. The use of scenario allows us to consider, in this case, two possible options: scenario one where BrownFarms is the supplier; scenario two where Jones Farms is the supplier. The latter would be represented as JonesFarms playsRole AppleSupplier.

\subsection{Reference Ontology Level 1 Axioms and Rules}

<Figure 11 here>

Figure 11. Level 1 axiom KFL for role requiring a system for a context

Constraints prevent inconsistent statements. KFL can model hard (IC hard) or soft constraints (IC soft). Integrity constraints are used to check data when it is loaded into the ontology. A hard IC must be obeyed and therefore can stop data being loaded that does not conform to the constraint. A soft IC produces a warning when data is loaded but data can still be loaded if this is ignored. Figure 11 illustrates an IC, it states that for all roles (Role ?r), a system (System ?s) must exists (exists (?s)), the role is related to the system (requiresA ?r ?s.).

\section{$<$ Figure 12 here >}

Figure 12. Level 1 rule KFL for a role requiring a system

Ontology rules are used to derive new information from the existing knowledge within the knowledgebase. Figure 12 shows an example of a rule, it states in KFL that if an instance of a role 'requiresA' specific system (requiresA ?x ?y), then that system also contains that role (systemContainsRole ?y ?x).

\section{Application of the Product-Service Systems Reference Ontology}

A constituent part of the FLEXINET project is a collaborative infrastructure with supporting services to implement a decision support system for representing, configuring and evaluating global product-service production networks (as illustrated in Figure 13). This Production Network Design configuration tool is characterised by three main services, these are:

- Economic and Risk Assessment Service: used to evaluate the impact of introducing innovations into an existing global production network. Innovations could be at the level of product (new materials, new design, new product line), at the level of production process (new production technologies, new supply chain, new logistic concepts) or at the level of service (e.g. diagnosis, maintenance, energy saving, environmental sustainability).

- Production-Service Coevolution Service: this service will provide typical business process 
schemas, instantiated in the diverse productservice scenarios (e.g. service adjunct with the product, service packaged with the product, service integrated with the product, service entangled with the product), different industrial sectors and domains, to help managers to implement the best production paradigm for product-service co-evolution.

- Production Network Evaluation Service: will evaluate and rank different possible alternatives of the product-service global production network, on the basis of a STEEP-oriented (Social Technological Economic Environmental Political sustainability) multi-criteria analysis.

These three main services are underpinned by the knowledge management framework which is built upon the FLEXINET reference ontology.

\section{$<$ Figure 13 here >}

Figure 13. FLEXINET architectural approach.

The Production Network Evaluation Services (PNES) application has the objective of defining information about product-service systems, so as to analyse the different ways to build a global production network in the GPN Representation.

In general, GPN Representation allows the visualisation of all elements of the network and their relationships. Users can update the network adding new nodes, defining new relationships, changing the existing ones, identifying inputs and outputs, etc. In addition, this application allows characterisation of the GPN in terms of properties describing each node.

At a conceptual level, each node of a GPN represents 'Facilities' and their relationships with other ones. A Facility is assigned to a specific geographical location and may contain systems. Every 'System' consumes a number of 'Inputs', uses a number of 'Resources', and produces a number of 'Outputs'.

The network creation occurs when the outputs of a facility are the inputs for other facility. The GPN is built as a chain of Inputs and Outputs that connect facilities in different geographical locations.

This application has the objective of defining information about the products, to enable the application to analyse the different ways to build a global production network in the GPN Representation.

Technology, understood as a 'Resource' needed to realise a process, is one of the elements used for the reasoning about the best potential GPN configuration for a new Product. A 'Product' is here defined either as a 'Good', a 'Service', or a combination of both.
$<$ Figure 14 here $>$

Figure 14. A GPN configuration example.

Resources are elements used by a System, but in contrast to Inputs, Resources are not transformed in the production process. In this sense, possible Resources range from available machinery to human skills. Thus, in addition to the characterisation of the GPN in terms of Facilities and Systems, it is useful for the reasoning to include information about Products (understood as Goods, Services or a Combination of both). For this task a Goods \& Services section is included as part of the GPN Configuration tool. There, the user will provide the characterisation of Goods, Services and the potential associations between them. These associations will contribute with essential data from End-User points of view to the reasoning category (along with the ontologies). As with the Systems, a Good (the same applies to service) is characterised in terms of Inputs, Outputs and Resources. Figure 14 sets out an example schematic view of the constituent parts used to configure a GPN. A GPN configuration application is used by the end users to configure a network relative to their needs. This application is supported by the Network Configuration Service, which, in turn applies the FLEXINET knowledge base supported by the ontology to reason about end users' needs and constraints to configure a GPN that satisfies them.

Based on the reference ontology structure, a knowledge base has been populated to satisfy the three end users. This enables queries to be actioned against the knowledge base to derive potential answers to the problems being posed.

An example of a query represented in KFL is set out in Figure 15. This query has been developed to ask a question relating to product specification, the query is "given an input to a GPN requires certain characteristics, list the suppliers that provide outputs that fulfil the specified input characteristics".

\section{$<$ Figure 15 here $>$}

Figure 15. GPN query for matching outputs to inputs.

It can be seen in the Figure 15 query that the GPN (?gpn) requires an input (?input1) with the characteristic ?c01. Suppliers containing an output that possess this characteristic (roleHasCharacteristic) are queried for. A set of example results for the query utilising a populated knowledge base are presented in Figure 16. This shows that two suppliers have been found that possess the one characteristic specified and provide details of the characteristic. 
<Figure 16 here>

Figure 16. GPN query results for matching outputs to inputs.

This provided example demonstrates the use and application of Roles specified within level 1 as applied to a global production network. Associated with this, Figure 17 depicts the representation of a GPN configuration example using the prototype FLEXINET PNES software tool. This shows that there are two companies playing the Role of suppliers providing inputs to the producer (linked with orange arrows), one company playing the Role of a producer (denoted by the factory symbol) and one company playing the role of a customer accepting outputs from the producer (linked with a green arrow).

\section{$<$ Figure 17 here $>$}

Figure 17. PNES representation of a global production network.

\section{Discussion}

Recent research attention has been focused upon the domains of enterprise and manufacturing interoperability but, as of yet, the domain of global production networks has very few examples of research relating to reference ontologies and the facilitation of interoperability. With this in mind, it has therefore been necessary to study reference ontologies that are related and international standards to understand whether or not they are applicable to the domain and context being studied but, also to enable a representative and consistent PSS reference ontology to be developed. This can sometimes promote a top down approach to the development of an ontology, therefore, another important aspect has been the input of the industrial partners involved. This has enabled the reference ontology levels to be concurrently developed with a bottom up approach, this can be a key component in countering any bias during development stages. Moreover such an approach places a focus upon the real needs of the main stakeholders within the FLEXINET research project. Utilising multicontext information and knowledge sources to develop the PSS reference ontology sets out a considered approach for the definition and formalisation of a representative reference ontology for productservice systems.

\section{Conclusions and Furtherwork}

This paper has illustrated a reference ontology for Product-Service Systems comprised of a higher level core or foundation ontology that can act as a base for the generation and building of formal reference ontologies, not only for global production networks but other domains that are related and have potential for interoperation. Level 1 of the PSS reference ontology presented herein contains the few key concepts necessary to model any system. This is a key aspect of the ontological approach which, has been formally modelled using the Knowledge Framework Language to produce a common logic based representation that is succinctly defined semantically.

The research approach and ideas put forward are actively being developed against a set of formalised FLEXINET industrial end user requirements and needs. Moreover the FLEXINET ontological research objective of 'define reference ontologies from which to base the flexible re-configuration of globalised production networks' is helping guide and focus the approach. Further development of the reference ontology is needed for levels two, three and four, against the FLEXINET industrial end user requirements, together with the IMKS [4], MSEE [11] and MCO [10] ontologies to expand, refine and advance the research.

A collaborative infrastructure with supporting services, underpinned by the reference ontology is currently being developed. The intentions of this are to test and implement a decision support system for the representation, configuration and evaluation of global product-service production networks. Industrial information and knowledge is being utilised to verify the approach and validate it against the end user requirements, thus, providing valuable feedback to further enhance the approach.

\section{Acknowledgements}

The research leading to these results has received funding from the European Community's $7^{\text {th }}$ Framework Programme under grant agreement $n^{\circ}$ NMP2-SL-2013-608627.

\section{References}

1. Vandermerwe, S. and Rada, J., 1988. Servitization of business: adding value by adding services. European Management Journal, vol. 6 no. 4, pp. 314324.

2. Coe, N.M., Dicken, P., Hess, M., 2007. Global production networks: realizing the potential. Eco- 
nomic Geography Research Group, Working Paper Series No. 05.07.

3. Young, R.I.M., Gunendran, A.G., Chungoora, N., Harding, J.A., Case, K., 2009. Enabling interoperable manufacturing knowledge sharing in PLM. Proceedings of the Sixth International Conference on Product Life Cycle Management PLM09, University of Bath, Bath, UK, July 6-8, Switzerland, Inderscience Enterprises Ltd., pp.130-138.

4. Young, R. I. M., Gunendran, A. G., CuttingDecelle, A. F., and Gruninger, M., 2007. Manufacturing knowledge sharing in PLM: a progression towards the use of heavy weight ontologies. International Journal of Production Research, 45(7), pp.1505-1519.

5. Usman, Z., Young, R.I.M., Chungoora, N., Case, K., Palmer, C. and Harding J.A., 2013. Towards a formal manufacturing reference ontology. International Journal of Production Research, 51(22), pages 6553-6572

6. Chungoora, N., Gunendran, G. A., Young, R. I. M., Usman, Z., Anjum, N. A., Palmer, C., Harding, J .A., Case, K., Cutting-Decelle, A-F., 2012. Extending Product Lifecycle Management for manufacturing knowledge sharing. Proceedings of the Institution of Mechanical Engineers Part B - Journal of Engineering Manufacture, 226 (A12), pp. 20472063.

7. International Standards Office, 2004. ISO 18629 1:2004, Industrial automation systems and integration -- Process specification language -- Part 1: Overview and basic principles. Genève: ISO.

8. International Standards Office, 2007. ISO/IEC 24707:2007 Information technology -- Common Logic (CL): a framework for a family of logic-based languages. Genève: ISO.

9. Imran, M., 2013. Towards an Assembly Reference Ontology for Assembly Knowledge Sharing. Ph.D. School of Mechanical and Manufacturing Engineering, Loughborough University, UK.

10. Hastilow, N., 2013. An Ontological Approach to Manufacturing Systems Interoperability in Dynamic Change Environments. Ph.D. School of Mechanical and Manufacturing Engineering, Loughborough University, UK.

11. MSEE Manufacturing Service Ecosystem. Available from http://www.msee-ip.eu/. [Accessed June 2014].

12. Athena, Advanced Technologies for Interoperability of Heterogeneous Enterprise Networks and their Application FP7 no 507849, 2006, POP* Revised Framework - Work Package A1.8. Amerigo, Supply Chain Mapping, Program Profit - IBB 2007, Zwischenberciht.

13. Pajkovska Goceva, S., 2013. Visibility and Transparency in Multilevel Supply Networks. Workshop on Innovative Service Infrastructures for Managing
Manufacturing Networks (ICSOC 2013), Berlin, Germany, 3rd December 2013.

14. International Standards Office, 2012. ISO 10303239:2012, Industrial automation systems and integration -- Product data representation and exchange -- Part 239: Application protocol: Product life cycle support. Genève: ISO.

15. IDEF0 Function Modeling Method. Available from: http://www.idef.com/idef0.htm [Accessed June 2014].

16. Foufou, S., Fenves, S.J., Bock, C., Rachuri, S. and Sriram, R.D., 2005. A Core Product Model for PLM with an illustrative XML implementation. Proceedings of the International Conference on Product Lifecycle Management. Lyons, France, $1^{\text {st }}$ March 2005.

17. Object Management Group, 2012, OMG Systems Modeling Language.

18. International Standards Office, 2012. ISO 10303233:2012, Industrial automation systems and integration -- Product data representation and exchange -- Part 233: Application protocol: Systems engineering. Genève: ISO.

19. Oliver, D.W., 2003. Draft 12 of Concept Model for Systems Engineering MDSD review. Available from: http://syseng.omg.org/SE_Conceptual\%20Model/S E_Conceptual_Model.htm [Accessed June 2014].

20. Object Management Group, 2010, Reference Metamodel for the Express Information Modeling Language Specification.

21. Reinhartz-Berger, I., Dori, D., and Katz, S., 2002. OPM/Web-object-process methodology for developing web applications. Annals of Software Engineering, 13(1-4), pp.141-161.

22. W3C, 2014, RDF Schema 1.1. Available from: http://www.w3.org/TR/2014/REC-rdf-schema20140225. [Accessed June 2014].

23. Highfleet Ontology Library Reference, 2014. Baltimore, MA: HIGHFLEET Inc.

24. International Standards Society, 2008. ISO/IEC 15288:2008 Systems and Software Engineering System lifecycle processes. Genève: ISO.

25. Banathy, B. H., 1992. A systems view of education: Concepts and principles for effective practice. Educational Technology.

26. Mizoguchi, R., Kozaki, K., \& Kitamura, Y. (2012, September). Ontological analyses of roles. In Computer Science and Information Systems (FedCSIS), 2012 Federated Conference on (pp. 489-496). IEEE. 


\title{
Reference Ontologies to Support the Development of Global Production Network Systems
}

\begin{abstract}
In competitive and time sensitive market places, organisations are tasked with providing Product Lifecycle Management (PLM) approaches to achieve and maintain competitive advantage, react to change and understand the balance of possible options when making decisions on complex multi-faceted problems, Global Production Networks (GPN) is one such domain in which this applies. When designing and configuring GPN to develop, manufacture and deliver product-service provision, information requirements that affect decision making become more complex. The application of reference ontologies to a domain and its related information requirements can enhance and accelerate the development of new product-service systems with a view towards the seamless interchange of information or interoperability between systems and domains.
\end{abstract}

This paper presents (i) preliminary results for the capture and modelling of end-user information, (ii) an initial higher level reference core ontology for the development of reference ontologies and (iii) the formal logical modelling of Level 1 of the FLEXINET reference ontology using a common logic based approach.

Keywords: product lifecycle management, global production networks, reference ontologies, interoperability, product service systems.

\section{Introduction}

The nature of competition dictates rivalry and in the domain of manufacturing industry the act of competing for supremacy in the design, production and selling of products. The 21 st century information age is forcing manufacturers to act differently to compete successfully and find different ways in which to not only source and manufacture products but also configure and then sell them to customers.

The servitisation of products i.e. 'the increased offering of fuller market packages or 'bundles' of customer focused combinations of goods, services, support, self-service and knowledge' [1] is proving to be an enticing form of selling products via services to customers. Whilst the benefits can be seemingly apparent and instant, the actuality is that there are many additional components that are necessary.

The challenge for manufacturing industry which is servitising products is, what is the most effective way to design, produce and sell a product together with it associated service components effectively, to form a Product-Service System (PSS)? At the heart of this is how to align and integrate a traditional product lifecycle viewpoint with a more modern service lifecycle to develop a PSS. Additional complexity is added to this approach when Global Production Networks (GPN) are to be configured and reconfigured and in the face of rapidly changing product-service requirements. By employing a GPN, organisations can adopt technology at a faster pace, lower costs and be more open to change $[1,2]$. But an important aspect must be considered carefully, that of information interoperability between suppliers, manufacturers and service provision mechanisms. This becomes paramount when configuring sizeable and diverse GPN across potentially large geographical areas and between widely varying domains and contexts. It can introduce a wide and varied range of risks and perturbations from diverse system processes and capabilities, to different legislation and laws. One such method that can mitigate these risks to information interoperability is the use and application of ontological reference models.

What can be derived from this is that organisations are tasked with providing product lifecycle management (PLM) approaches and solutions to enable the sharing, use and reuse of information and knowledge, the main objective of this being to achieve and maintain competitive advantage for their Product-Service Systems [3]. They must be able to react to change and understand the balance of possible options when making decisions on complex multi-faceted problems, GPN is one such domain in which this applies.

There are a number of interesting formal ontologies that have been developed. The first is the Interoperable Manufacturing Knowledge Systems (IMKS) project, a UK EPSRC funded project, demonstrated the potential of reference ontologies for interoperable manufacturing knowledge sharing [4] across a range of company groups operating within and across product life cycle phases. These groups may work across multiple organisations and make use of a variety of software systems. The IMKS project explored the concept of a reference ontology to afford an effective basis for concept specialisation across a range of manufacturing systems within an individual enterprise. As part of this it developed a set of core concepts to specifically enable the sharing of knowledge across design and production domains. Design and production concepts were specialised from generic foundation 
ontology concepts in order to provide the required level of interoperability [5].

The IMKS project exploited a Common Logicbased ontology language to express the core concepts. In order to avoid subjective interpretation and to model relationships consistently between concepts, the underlying semantics upon which the concepts are based need to be formalised. Chungoora [6] justified the use of Common Logic to capture manufacturing concepts, discovering that in order to model complex manufacturing domains the capabilities of Common Logic are preferable to the less expressive capability of the Web Ontology Language (OWL). The use of Common Logic also enables the utilisation of the Process Specification Language (PSL) [7], as PSL is written in the Common Logic Interchange Format (CLIF) [8]. PSL provides formal process reasoning enabling the capture of generic manufacturing process semantics.

Imran [9] extended the IMKS concept to consider the use of formal Common Logic-based ontologies to support knowledge sharing within the assembly domain. Imran [9] proposed a framework of key reference concepts specialised from a generic foundation supporting the creation of interoperable application specific ontologies.

Hastilow [10] has also progressed the work of the IMKS project, employing a Common Logicbased approach applied to systems interoperability. Hastilow [10] used a core concept ontology to describe manufacturing systems, extending the ontology coverage across the product lifecycle and considering interoperation between defined systems. Hastilow [10] developed a Manufacturing Systems ontology applicable to any Manufacturing Systems domain.

Two European Framework Package 7 (FP7) projects have produced work that is aligned with the domain in question, those being the Manufacturing Service EcoSystem (MSEE) [11] FP7 project and the POP* methodology created by the Athena FP7 project [12]. The Manufacturing Service EcoSystem (MSEE) FP7 project aims to produce "new Virtual Factory Industrial Models where service orientation and collaborative innovation will support a new renaissance of Europe in the global manufacturing context" [11]. MSEE considers the hierarchical modelling of tangible and intangible manufacturing assets. MSEE utilises formal semantics but is based on OWL Description Logic so, whilst it provides an effective framework from which to draw manufacturing concepts, FLEXINET is able to extend MSEE capabilities through the more expressive manufacturing business modelling provided by Common Logic.

The POP* [12] methodology aimed to develop ways of capturing the design and management issues which occur during enterprise collaboration. The POP* (Process, Organisation, Product and others) language provides a set of concepts to support model exchange between collaborating enterprises. POP* consists of five dimensions: Process, Organisation, Product, Decision and Infrastructure. The POP* objective was to provide a mapping methodology from several enterprise modelling languages to the POP* format. The aim of this was to enable interoperability between collaborating enterprises using different modelling languages. The POP* language utilises the object-role-action paradigm. According to this approach, there are two basic domains in an enterprise: object domain (both physical and information objects) and action domain (such as activity, process, tasks, operations, etc.). The concept of role enables these two domains to be related. Indeed, various objects play different roles in different actions (for example, objects plays roles as input, output, resource and control in a process) [12].

The Integrated Supply Network Ontology (iSNO) is related work, developed to support the visualisation and navigation through multidimensional supply networks initiated during the amerigo project [13]. The objective of iSNO was to develop a platform for gathering and maintaining the information for visualising and analyses of Supply Networks, in a form of a Strategic Supply Network Map. The iSNO - Strategic Supply Network Map should support the requirements for providing a holistic view of the supply network, distributive modelling and modification, integrating information from different sources,.

Relative to the development of reference ontologies for GPN, two international standards are significant, the first is the afore mentioned ISO 18629:2004, Industrial automation systems and integration, Process Specification Language [7]. This standard provides intuitions for reasoning about various forms of processes and thus forms an effective foundation for capturing process-related meaning [4]. The intent of the PSL Core is to provide a set of intuitive primitives adequate for describing the fundamentals of manufacturing processes, defined as formal axioms. The second applicable standard is ISO 10303-239:2012 [14] which, concerns Product LifeCycle Support (PLCS), specifies the information required to support a product throughout its life [14] and a structure for information exchange. This PLCS standard supports feedback of information acquired during product usage, including feedback on product usage, support activities and resources used to provide support. PLCS contains an activity model defined in the IDEF0 modelling language [15] and an information model written in the Express information modelling language [15]. The activity mod- 
el describes an application in terms of its processes and information flows. The information model has three key concepts (product, activity and resource) each of which may be associated with properties, states or locations. PLCS makes the important distinction between planned products (i.e. those still at the design stage) and realised products (i.e. those in use).

Another aspect aligned to standards that is relevant is the Core Product Model from the National Institution of Standards and Technology (NIST) [16], it captures product model data over the lifecycle of the product. The product is modelled in terms of three concepts: function (what the product is supposed to do), form (in terms of geometry and material) and behaviour (how a form implements its function) and is represented in UML. The Core Product Model defines core manufacturing concepts such as Feature, Form and FormFeature.

A number of systems modelling approaches have standardised concept models that are relevant and of importance. The Systems Engineering Conceptual Model was developed by members from the International Council on Systems Engineering (INCOSE), the AP233 committee, and SysML development group and represents a consensus on the definition of some of the key system modelling concepts $[17,18]$. The Systems Engineering Conceptual Model is expressed as a UML class diagram and captures essential concepts of systems engineering such as System, Requirement, Stakeholder, Behaviour and Environment [19]. The Systems Engineering Conceptual Model was used as input to requirements for SysML. SysML is a general purpose modelling language intended to model systems from a broad range of industrial domains. SysML is graphical language which extends UML and provides a foundation for representing the requirements, behaviour, structure and properties of a system. AP233 is an information exchange model for the exchange of data between Systems Engineering, Systems Architecture Description and related tools. It could be used to exchange information between a SysML and another Systems Engineering application. AP233 is based on the Express modelling language [20] and is a product-centric information model containing concepts of Product, Product Version and Product View Definitions [18]

The Object Process Methodology (OPM) [21] unifies function, structure and behaviour within a single model. OPM is a graphical representation language which considers the interactions between entities and the processes which act upon them. It can be translated into natural language (Object Process Language (OPL)) and RDF [22]. OPM is better able to model processes and interaction between systems than SysML.
The premise of this paper is to put forward the notion that the application of formal reference ontologies to a domain and its related information requirements so as to enhance and accelerate the development of new PSS with a view towards the seamless interchange of information or interoperability between systems and domains. This approach is being developed as part of the research being undertaken in the EU FP7 FLEXINET project.

This paper is structured as follows. Section 2 discusses the FLEXINET project and its purpose. Section 3 sets out the methodological approach and development of reference ontologies for productservice systems. Section 4 looks at the application of the FLEXINET reference ontology. Section 5 puts forward a discussion of the aspects addressed in this paper and Section 6 draws the paper to a close with conclusions and further work.

\section{The FLEXINET View}

FLEXINET aims to support decision-making in the early design of global production network configurations based on the implementation of new complex technologies. FLEXINET will apply advanced solution techniques to the provision of a set of Intelligent Production Network Configuration Services that can support the design of high quality manufacturing networks, understanding the costs and risks involved in network re-configuration, and then mitigating the impact of system incompatibilities as networks change over time. These are fundamental requirements for high quality decisionmaking in the early design of intelligent manufacturing system networks. These innovative concepts will enable a fast and efficient response to market variations and be easily adaptable across industrial sectors. The FLEXINET concept is illustrated in Figure 1.

FLEXINET takes the view that new manufacturing business modelling methods are needed that can model business cases and identify the critical network relations that underlie the business operation. Such methods and models are essential to the ability to define both the production network knowledge that must be captured and the queries that must be made if new business configuration possibilities are to be evaluated. Product servitisation adds to the complexity of this problem as the relationships between product lifecycles and service lifecycles also need to be understood and their impact on production system networks specified within the resulting business models.

The main aims of the FLEXINET ontological research are the following, (i) document key semantic concepts, knowledge constraints and interrelationships in the context of globalised produc- 
tion networks, (ii) structure and formally model concepts, relationships, constraints and related facts to provide an underpinning environment against which specific network configuration designs can be evaluated and (iii) develop methods for ontology querying from which to evaluate the compliance of potential production network configurations from both OEM and SME perspectives. In essence, the general approach of the FLEXINET project is to provide a common foundation of ontologies and knowledge bases to support reconfigurable software services and applications, as depicted in Figure 2 .

\section{$<$ Figure 1 here>}

Figure 1. The FLEXINET Concept: Intelligent Production Network Configuration Services.

$<$ Figure 2 here>

Figure 2. The FLEXINET approach to supporting software services with ontologies and knowledge bases.

\section{A Reference Ontology for Product- Service Systems}

The starting point for the development of the FLEXINET formal reference ontology for productservice systems has been three industrial case studies which have provided a solid base for the elicitation and capture of information and knowledge. In addition to this, the work from the Interoperable Manufacturing Knowledge Systems (IMKS) project, the Manufacturing Service Ecosystem (MSEE) project and the Manufacturing Information ontological model set out by Hastilow [10] is being assessed for applicability to the GPN and PSS domains.

\section{$<$ Figure 3 here >}

Figure 3. The supporting formal ontologies and knowledge bases.

The FLEXINET approach focuses on the intelligent configuration of a network of products or product-service systems, to support interoperability between systems and domains the approach utilises a core foundation ontology. Figure 3 provides a diagram showing the benefits of such an approach, the intent being to develop domain specific ontologies from a common core or reference ontology. The benefit of such a method is that by developing systems from a common foundation, it enables easier communication between different types of systems and in this context, across different production networks.

To enable ease of construction and to facilitate re-use across domains the FLEXINET ontology is organised into five levels, as illustrated in Figure 4. Each level inherits concepts from and provides additional concepts to the level above, the ontology becoming more domain specific with each level. Five levels are needed to specialise the concepts from the foundation to the specific domains. Figure 4 shows example domains at each level, the scope of FLEXINET being indicated in red.

<Figure 4 here>

Figure 4. The FLEXINET ontology levels

Level 0 Core consists of foundation concepts applicable to all domains, having nothing to do directly with Product-Service Lifecycle Systems. The foundation concepts include time, events, aggregation and lists and are derived from the Highfleet Upper Level Ontology (ULO) [23]. Level 1 contains the few key concepts necessary to model any system. A system transforms inputs into outputs and is defined as "a combination of interacting elements organized to achieve one or more stated purposes" [24]. Level 2 uses Banathy's classification [25] to specialise systems into "Natural Systems" and "Designed Systems". Natural systems are living systems of all kinds, the solar system and the Universe. Designed systems are man-made creations, including fabricated physical systems, conceptual knowledge and purposeful creations. FLEXINET will provide decision support for product lifecycle management and, as this requires human input (i.e. input from a living system), the scope of FLEXINET covers purposeful creations and overlaps into natural systems.

Level 3 further differentiates designed systems, FLEXINET being concerned with Manufacturing Business Systems which are specialised within Level 4. At this level FLEXINET considers Product-Service Lifecycle Systems, implemented as Global Production Networks. The lifecycle phases are denoted as design, produce, operate and end of life (including disposal, recycling and remanufacturing). The focus of FLEXINET is how to design a GPN to produce and operate a product-service. The main area FLEXINET considers within the Product-Service Lifecycle is "Produce" (producing the product) but the scope also overlaps into "Design" (of the network) and "Operate" as the operation of the product and the service needs to be considered. Level 5 applies Level 4 to case studies creating enterprise specific domains.

Figure 5 sets out the level 1 ontology. It applies the Unified Modelling Language (UML) [17] technique to describe the details about the concepts and relations necessary to specify a system. This ontol- 
ogy level utilises the concept TimeSpan (inherited from Level 0) and contains two parent concepts: Basic and Role. A TimeSpan includes the first and last instants of a date and all the instances in between [23]. A Basic concept [26] is independent of the system or context, its definition does not depend on another concept and an instance of a Basic always retains its identity as such. Examples of Basic are information and material. A Basic can be comprised of Basics, e.g. "bottled water" is comprised of the materials "bottle", "cap" and "mineral water". A System is subtype of Basic and provides a context for the Roles it contains (shown via the "depends on" relation and the composition filled diamond in Figure 5).

The definition of a Role depends on a context, an instance of a Role cannot exist without a context and the playsRole relation is transitory. For example, a person Joe has a Role as a lecturer (context "university") and changes Role to a consultant (context "enterprise"), whereas the Basic "bottle" is always a "bottle". It can be seen that a lecturer Role cannot exist without the university context, if the university closes the lecturer role ceases to exist. Roles may be comprised of Roles (e.g. a lecturer Role may be comprised of administration, teaching and staff Roles).

$<$ Figure 5 here >

Figure 5. FLEXINET Level 1 Systems Ontology

A Basic plays a Role for certain TimeSpans, modelled in the ternary relation "playsRole". For example in the context of a manufacturing organization system, the Basic "bottled water" can play the Role of a Product during the TimeSpan of the system. Within a University a person could play the Role of a lecturer for a TimeSpan of five years, become unemployed and then play the Role of a lecturer again for a further TimeSpan.

A Basic can play more than one Role at the same time (e.g. a person could be a lecturer and a parent). A Role can be played by more than one Basic, e.g. the role of a laundry would require a washer and a drier. There is no requirement for a Basic to play a Role (shown by the $0 .{ }^{*}$ multiplicity next to the Role concept in Figure 5). Role and Basic concepts exist separately and have separate identities. There is also no requirement for a Role to be played by a Basic, enabling empty Roles to be modelled (e.g. if a person Joe left his Role as a lecturer the Role would still exist as a lecturer vacancy).

A Basic may affect the state of a role, e.g. the size of a Basic "bottled water" playing the Role of a product could influence the dimensions required for a packing resource Role. Additionally a Role may affect the state of a Role, e.g. within the lecturer Role more duties allotted to the administration Role would cause duties to be removed from the teaching Role).

Scenario concepts are defined within the FLEXINET reference ontology in order to provide a method to describe multiple alternative instantiations of global production networks. Additionally scenarios can be composed of scenarios.

The four key Roles which describe a system are input, output, resource and control. An input represents what is brought into and is transformed or consumed by the system to produce outputs. An output represents what is brought out from or is produced by the system. A resource is used by or supports the execution of the system. A control is a condition required to produce correct system output $[12,15]$.

The FLEXINET ontological approach is applying the Knowledge Framework Language (KFL) this is a heavyweight ontology language based upon Common Logic [8]. This KFL code represents the formal ontology code that will be used to support FLEXINET services and applications. This approach is being applied due to its improved expressiveness as put forward by Chungoora et al. [6].

<Figure 6 here>

Figure 6. Level 1 context in KFL

For each reference ontology level within the KFL code a context must be stated so as to uniquely identify the concepts relative to a given perspective, in this instant the perspective is level 1. Figure 6 shows the KFL code for the Level context statement. The first line states 'Use MLO', this is the Highfleet Middle Level Ontology (MLO). The purpose of this is a reference point to a general top level ontological lexical resource to be used by the FLEXINET reference ontology. Such an ontology contains concepts useful to many perspectives. The second line 'Ctx 1SYSCtx' defines the context (Ctx) as the FLEXINET Level 1 Systems (SYS) Context (1SYSCTx). The third line 'Inst UserContext', identifies that 1SYSCTx is an Instance (Inst) of UserContext. UserContext is a MLO concept, not to be mistaken with Level 5 End User contexts. The final line states that it inherits from the MLO, i.e. includes the concepts from the MLO, in addition to the user defined concepts.

$<$ Figure 7 here>

Figure 7. Level 1 property KFL for 'basic' 
Properties are frames that allow concepts to be defined. Figure 7 illustrates the property 'Basic' (Prop Basic) from the level 1 UML diagram in Figure 5. It is an instance of a type (Inst Type), as such a type is something that always exists and additionally it is an instance of a non-logical functor (Inst NonLogicalFunctor) and hence is infinitely valued. It has a super-property (sup) of a Particular (things that are unique) contained within the Highfleet MLO. 'PartitionedBy' states that the only sub-properties of Basic can only be 'System', 'Energy', 'Material' and 'Information' (as per the UML diagram in Figure 5), additionally 'PartitionedBy' implies that any instances of basic subproperties are pairwise disjoint, i.e. an instance of a sub-property cannot be an instance of another subproperty, for example Gas_ID_27 cannot be an instance of Energy and Material. The final part of the KFL code is a 'rem' statement. These are textual statements within the code not meant for computation, providing more information for user comprehension of the specific items of KFL code. For property 'Basic' the rem statement defines what a Basic is and its sub-properties. '/sym' is a hyperlink to other items or relations within the ontology.

\section{$<$ Figure 8 here $>$}

Figure 8. Level 1 property KFL for 'role'

Figure 8 sets out the Role property. It is an instance of a Type and has a super-property (sup) of MLO.AbstractEntity (i.e. does not have the relationships MLO.LocatedIn). It is 'disjointWith' a Basic, i.e. an instance of role cannot also be an instance of a basic. The rem statement explains meaning of the property Role, in this instance, all roles include AbstractEntities that participates in systems, that a role cannot exist without a context, that all Roles are pairwise disjoint and as per the UML representation a Basic can play more than one Role.

\section{$<$ Figure 9 here >}

Figure 9. Level 1 rule KFL code for a scenario

A new concept addition at level 1 is the concept, or "property" in KFL terminology, of Scenario (see Figure 9). Scenario concepts are defined within the FLEXINET reference ontology in order to provide a method to describe multiple alternative instantiations of global production networks. It is defined at level 1 in order to catch its relationships with $\mathrm{Ba}-$ sics and Roles.

<Figure 10 here>
Figure 10. Level 1 relationship KFL for 'playsRole'

Figure 10 depicts the KFL code for, the PlaysRole relationship. It is an instance of a ternary relationship ('Inst TernaryRel') between three properties and a NonRigid relationship ('RigidRel'), i.e. these relationships will only hold over a particular timespan. 'Sig Basic Role Scenario' states the properties of the arguments of the relationship i.e. in this case the relation must be between a basic a role and a scenario.. 'Args' are strings that provide more detailed descriptions of argument properties. 'Lex' is a string template intended to provide a human-readable expression of its semantics.

It is noteworthy that while the UML model shows a quaternary relation, ECLIF provides an operator "HoldsIn" which provides the equivalent of the "timespan" shown in Figure 5.

Utilising this relationship and the three concepts of Basic, Role and Scenario we can start to model useful GPN relationships. Consider two possible apple suppliers to a drinks manufacturer, those of BrownFarms and JonesFarms. These are two instances of basic that play the role of suppliers. The use of scenario allows us to consider, in this case, two possible options: scenario one where BrownFarms is the supplier; scenario two where Jones Farms is the supplier. The latter would be represented as JonesFarms playsRole AppleSupplier.

<Figure 11 here>

Figure 11. Level 1 axiom KFL for role requiring a system for a context

Constraints prevent inconsistent statements. KFL can model hard (IC hard) or soft constraints (IC soft). Integrity constraints are used to check data when it is loaded into the ontology. A hard IC must be obeyed and therefore can stop data being loaded that does not conform to the constraint. A soft IC produces a warning when data is loaded but data can still be loaded if this is ignored.

<Figure 11 here>

Figure 11 illustrates an IC, it states that for all roles (Role ?r), a system (System ?s) must exists (exists (?s)), the role is related to the system (requiresA ?r ?s.).

\section{<Figure 12 here>}

Figure 12. Level 1 rule KFL for a role requiring a system 
Ontology rules are used to derive new information from the existing knowledge within the knowledgebase.

$<$ Figure 12 here>

Figure 12 shows an example of a rule, it states in KFL that if an instance of a role 'requiresA' specific system (requiresA ?x ?y), then that system also contains that role (systemContainsRole ?y ?x).

\section{Application of the Product-Service Systems Reference Ontology}

A constituent part of the FLEXINET project is a collaborative infrastructure with supporting services to implement a decision support system for representing, configuring and evaluating global product-service production networks (as illustrated in

<Figure 13 here>

Figure 13). This Production Network Design configuration tool is characterised by three main services, these are:

- Economic Risk Assessment Service: used to evaluate the impact of introducing innovations into an existing global production network. Innovations could be at the level of product (new materials, new design, new product line), at the level of production process (new production technologies, new supply chain, new logistic concepts) or at the level of service (e.g. diagnosis, maintenance, energy saving, environmental sustainability).

- Production Service Coevolution Service: this service will provide typical business process schemas, instantiated in the diverse productservice scenarios (e.g. service adjunct with the product, service packaged with the product, service integrated with the product, service entangled with the product), different industrial sectors and domains, to help managers to implement the best production paradigm for product-service co-evolution.

- Production Network Evaluation Service: will evaluate and rank different possible alternatives of the product-service global production network, on the basis of a STEEP-oriented (Social Technological Economic Environmental Political sustainability) multi-criteria analysis.

These three main services are underpinned by the knowledge management framework which is built upon the FLEXINET reference ontology.
$<$ Figure 13 here >

Figure 13. FLEXINET architectural approach

The Production Network Evaluation Services (PNES) application has the objective of defining information about product-service systems, so as to analyse the different ways to build a global production network in the GPN Representation.

$<$ Figure 15 here $>$

Figure 15 depicts the representation of a GPN configuration example.

In general, GPN Representation allows the visualisation of all elements of the network and their relationships. Users can update the network adding new nodes, defining new relationships, changing the existing ones, identifying inputs and outputs, etc. In addition, this application allows characterisation of the GPN in terms of properties describing each node.

At a conceptual level, each node of a GPN represents 'Facilities' and their relationships with other ones. A Facility is assigned to a specific geographical location and may contain systems. Every 'System' consumes a number of 'Inputs', uses a number of 'Resources', and produces a number of 'Outputs'.

The network creation occurs when the outputs of a facility are the inputs for other facility. The GPN is built as a chain of Inputs and Outputs that connect facilities in different geographical locations.

This application has the objective of defining information about the products, to enable the application to analyse the different ways to build a global production network in the GPN Representation.

Technology, understood as a 'Resource' needed to realise a process, is one of the elements used for the reasoning about the best potential GPN configuration for a new Product. A 'Product' is here defined either as a 'Good', a 'Service', or a combination of both.

<Figure 14 here>

Figure 14. A GPN configuration example.

Resources are elements used by a System, but in contrast to Inputs, Resources are not transformed in the production process. In this sense, possible Resources range from available machinery to human skills. Thus, in addition to the characterisation of the GPN in terms of Facilities and Systems, it is useful for the reasoning to include information about Products (understood as Goods, Services or a Combination of both). For this task a Goods \& Services section is included as part of the GPN 
Configuration tool. There, the user will provide the characterisation of Goods, Services and the potential associations between them. These associations will contribute with essential data from End-User points of view to the reasoning category (along with the ontologies). As with the Systems, a Good (the same applies to service) is characterised in terms of Inputs, Outputs and Resources. Figure 14 sets out an example schematic view of the constituent parts used to configure a GPN. A GPN configuration application is used by the end users to configure a network relative to their needs. This application is supported by the Network Configuration Service, which, in turn applies the FLEXINET knowledge base supported by the ontology to reason about end users' needs and constraints to configure a GPN that satisfies them. Associated with this,

$<$ Figure 15 here $>$

Figure 15 depicts the representation of a GPN configuration example using the prototype FLEXINET PNES software tool.

<Figure 15 here>

Figure 15. PNES representation of a global production network

\section{Discussion}

Recent research attention has been focused upon the domains of enterprise and manufacturing interoperability but, as of yet, the domain of global production networks has very few examples of research relating to reference ontologies and the facilitation of interoperability. With this in mind, it has therefore been necessary to study reference ontologies that are related and international standards to understand whether or not they are applicable to the domain and context being studied but, also to enable a representative and consistent PSS reference ontology to be developed. This can sometimes promote a top down approach to the development of an ontology, therefore, another important aspect has been the input of the industrial partners involved. This has enabled the reference ontology levels to be concurrently developed with a bottom up approach, this can be a key component in countering any bias during development stages. Moreover such an approach places a focus upon the real needs of the main stakeholders within the FLEXINET research project. Utilising multicontext information and knowledge sources to develop the PSS reference ontology sets out a considered approach for the definition and formalisation of a representative reference ontology for productservice systems.

\section{Conclusions and Furtherwork}

This paper has illustrated a reference ontology for Product-Service Systems comprised of a higher level core or foundation ontology that can act as a base for the generation and building of formal reference ontologies, not only for global production networks but other domains that are related and have potential for interoperation. Level 1 of the PSS reference ontology presented herein contains the few key concepts necessary to model any system. This is a key aspect of the ontological approach which, has been formally modelled using the Knowledge Framework Language to produce a common logic based representation that is succinctly defined semantically.

The research approach and ideas put forward are actively being developed against a set of formalised FLEXINET industrial end user requirements and needs. Moreover the FLEXINET ontological research objective of 'define reference ontologies from which to base the flexible re-configuration of globalised production networks' is helping guide and focus the approach. Further development of the reference ontology is needed for levels two, three and four, against the FLEXINET industrial end user requirements, together with the IMKS [4], MSEE [11] and MCO [10] ontologies to expand, refine and advance the research.

A collaborative infrastructure with supporting services, underpinned by the reference ontology is currently being developed. The intentions of this are to test and implement a decision support system for the representation, configuration and evaluation of global product-service production networks. Industrial information and knowledge is being utilised to verify the approach and validate it against the end user requirements, thus, providing valuable feedback to further enhance the approach.

\section{Acknowledgements}

The research leading to these results has received funding from the European Community's $7^{\text {th }}$ Framework Programme under grant agreement $n^{\circ}$ NMP2-SL-2013-608627.

\section{References}

1. Vandermerwe, S. and Rada, J., 1988. Servitization of business: adding value by adding services. Euro- 
pean Management Journal, vol. 6 no. 4, pp. 314324.

2. Coe, N.M., Dicken, P., Hess, M., 2007. Global production networks: realizing the potential. Economic Geography Research Group, Working Paper Series No. 05.07.

3. Young, R.I.M., Gunendran, A.G., Chungoora, N., Harding, J.A., Case, K., 2009. Enabling interoperable manufacturing knowledge sharing in PLM. Proceedings of the Sixth International Conference on Product Life Cycle Management PLM09, University of Bath, Bath, UK, July 6-8, Switzerland, Inderscience Enterprises Ltd., pp.130-138.

4. Young, R. I. M., Gunendran, A. G., CuttingDecelle, A. F., and Gruninger, M., 2007. Manufacturing knowledge sharing in PLM: a progression towards the use of heavy weight ontologies. International Journal of Production Research, 45(7), pp.1505-1519.

5. Usman, Z., Young, R.I.M., Chungoora, N., Case, K., Palmer, C. and Harding J.A., 2013. Towards a formal manufacturing reference ontology. International Journal of Production Research, 51(22), pages 6553-6572

6. Chungoora, N., Gunendran, G. A., Young, R. I. M., Usman, Z., Anjum, N. A., Palmer, C., Harding, J .A., Case, K., Cutting-Decelle, A-F., 2012. Extending Product Lifecycle Management for manufacturing knowledge sharing. Proceedings of the Institution of Mechanical Engineers Part B - Journal of Enginering Manufacture, 226 (A12), pp. 20472063.

7. International Standards Office, 2004. ISO 186291:2004, Industrial automation systems and integration -- Process specification language -- Part 1: Overview and basic principles. Genève: ISO.

8. International Standards Office, 2007. ISO/IEC 24707:2007 Information technology -- Common Logic (CL): a framework for a family of logic-based languages. Genève: ISO.

9. Imran, M., 2013. Towards an Assembly Reference Ontology for Assembly Knowledge Sharing. Ph.D. School of Mechanical and Manufacturing Engineering, Loughborough University, UK.

10. Hastilow, N., 2013. An Ontological Approach to Manufacturing Systems Interoperability in Dynamic Change Environments. Ph.D. School of Mechanical and Manufacturing Engineering, Loughborough University, UK.

11. MSEE Manufacturing Service Ecosystem. Available from http://www.msee-ip.eu/. [Accessed June 2014].

12. Athena, Advanced Technologies for Interoperability of Heterogeneous Enterprise Networks and their Application FP7 no 507849, 2006, POP* Revised Framework - Work Package A1.8. Amerigo, Supply Chain Mapping, Program Profit - IBB 2007, Zwischenberciht.
13. Pajkovska Goceva, S., 2013. Visibility and Transparency in Multilevel Supply Networks. Workshop on Innovative Service Infrastructures for Managing Manufacturing Networks (ICSOC 2013), Berlin, Germany, 3rd December 2013.

14. International Standards Office, 2012. ISO 10303239:2012, Industrial automation systems and integration -- Product data representation and exchange -- Part 239: Application protocol: Product life cycle support. Genève: ISO.

15. IDEF0 Function Modeling Method. Available from: http://www.idef.com/idef0.htm [Accessed June 2014].

16. Foufou, S., Fenves, S.J., Bock, C., Rachuri, S. and Sriram, R.D., 2005. A Core Product Model for PLM with an illustrative XML implementation. Proceedings of the International Conference on Product Lifecycle Management. Lyons, France, $1^{\text {st }}$ March 2005.

17. Object Management Group, 2012, OMG Systems Modeling Language.

18. International Standards Office, 2012. ISO 10303233:2012, Industrial automation systems and integration -- Product data representation and exchange -- Part 233: Application protocol: Systems engineering. Genève: ISO.

19. Oliver, D.W., 2003. Draft 12 of Concept Model for Systems Engineering MDSD review. Available from: http://syseng.omg.org/SE_Conceptual\%20Model/S E_Conceptual_Model.htm [Accessed June 2014].

20. Object Management Group, 2010, Reference Metamodel for the Express Information Modeling Language Specification.

21. Reinhartz-Berger, I., Dori, D., and Katz, S., 2002. OPM/Web-object-process methodology for developing web applications. Annals of Software Engineering, 13(1-4), pp.141-161.

22. W3C, 2014, RDF Schema 1.1. Available from: http://www.w3.org/TR/2014/REC-rdf-schema20140225. [Accessed June 2014].

23. Highfleet Ontology Library Reference, 2014. Baltimore, MA: HIGHFLEET Inc.

24. International Standards Society, 2008. ISO/IEC 15288:2008 Systems and Software Engineering System lifecycle processes. Genève: ISO.

25. Banathy, B. H., 1992. A systems view of education: Concepts and principles for effective practice. Educational Technology.

26. Mizoguchi, R., Kozaki, K., \& Kitamura, Y. (2012, September). Ontological analyses of roles. In Computer Science and Information Systems (FedCSIS), 2012 Federated Conference on (pp. 489-496). IEEE. 


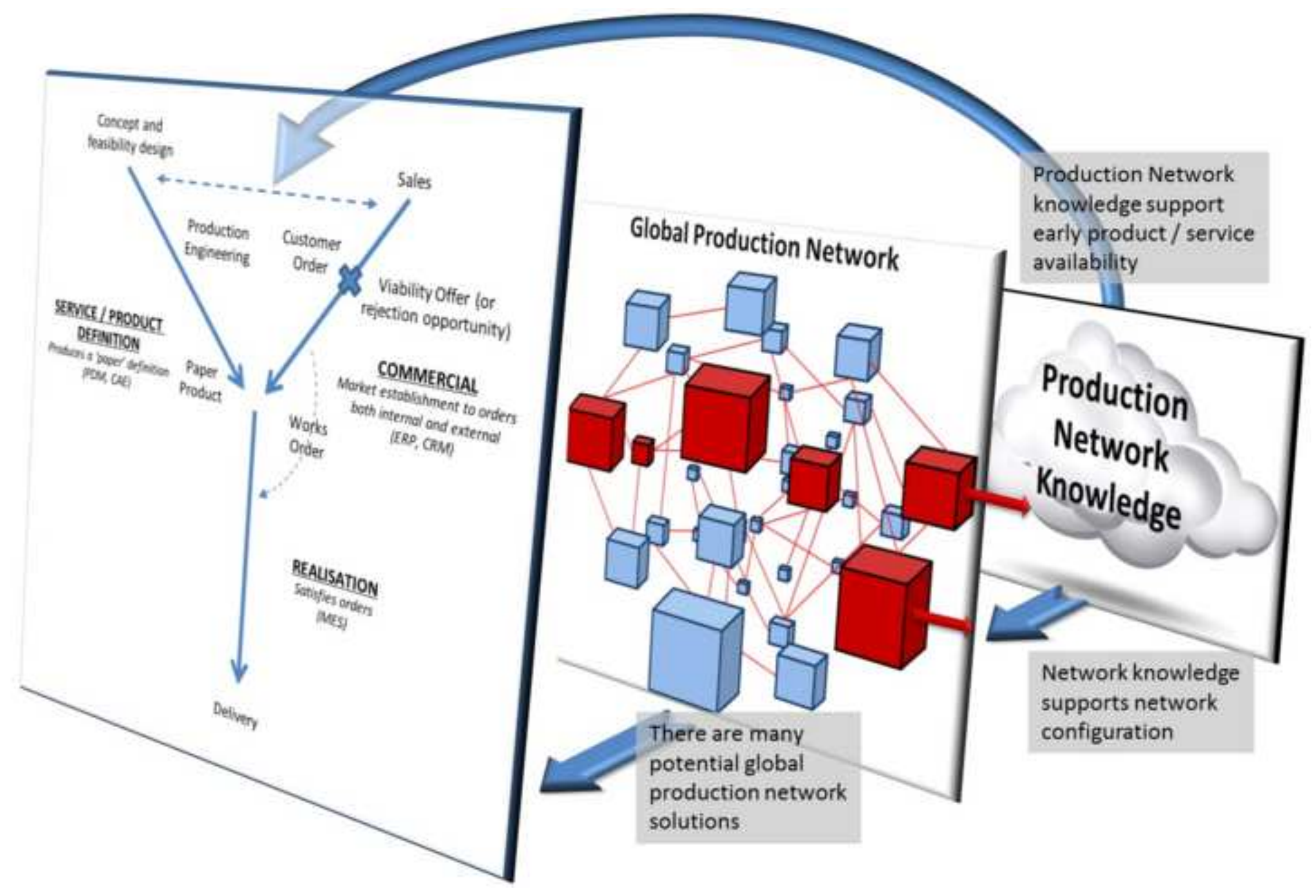


FLEXINET Front End

FLEXINET Services

FLEXINET Knowledge Base

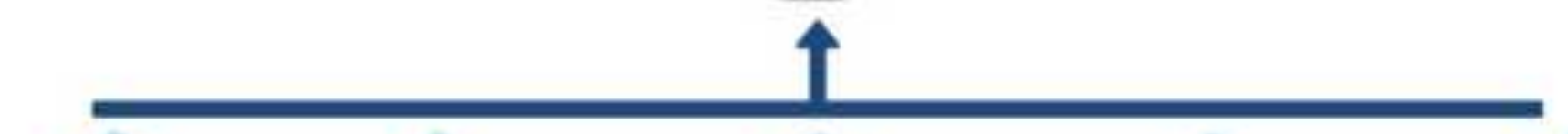

FLEXINET Applications
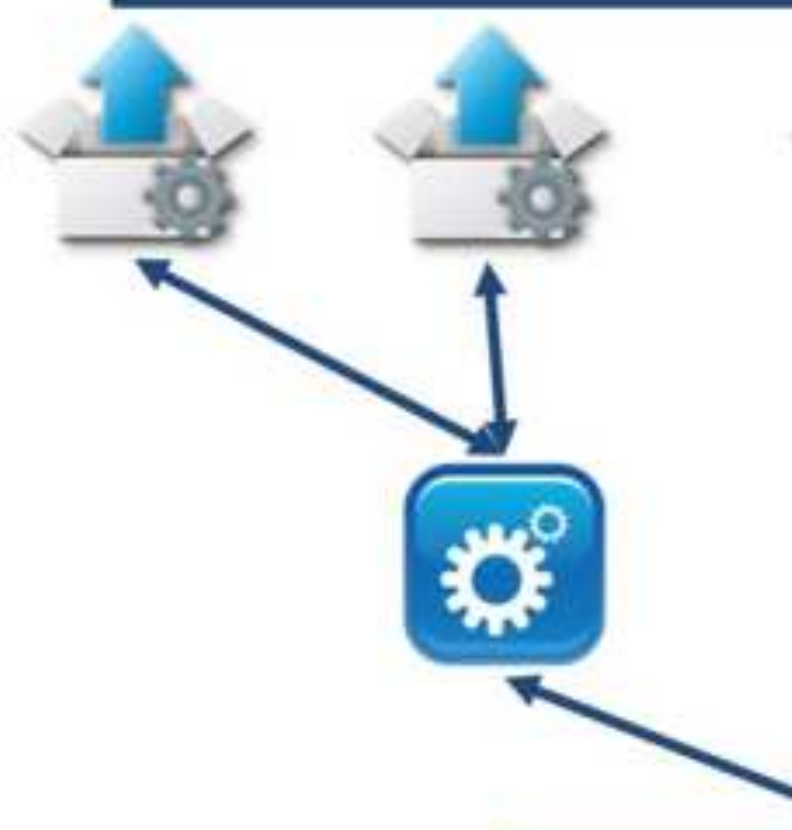

$\Delta$

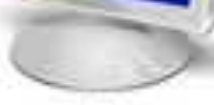
FLEXINET Knowledge Base
(Facts + Ontology)

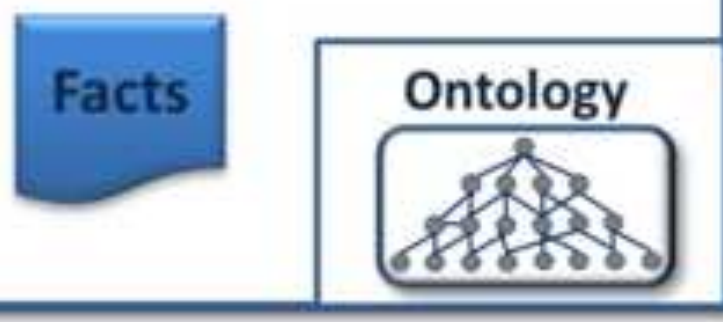



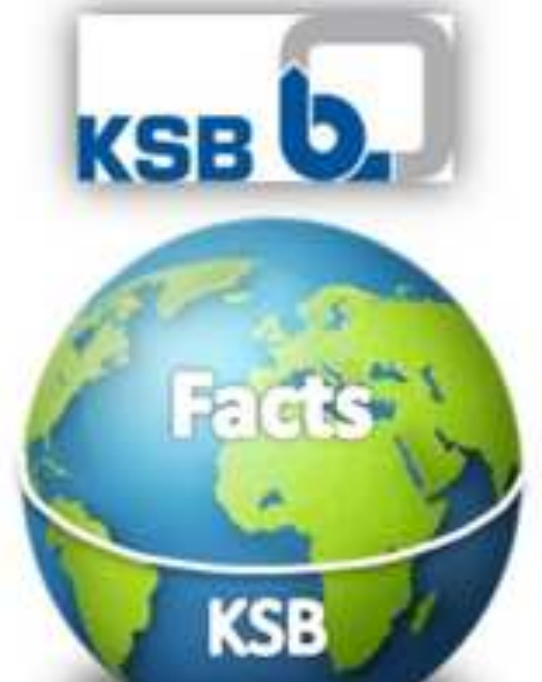

Ontologies

\section{(i) InDesIT}

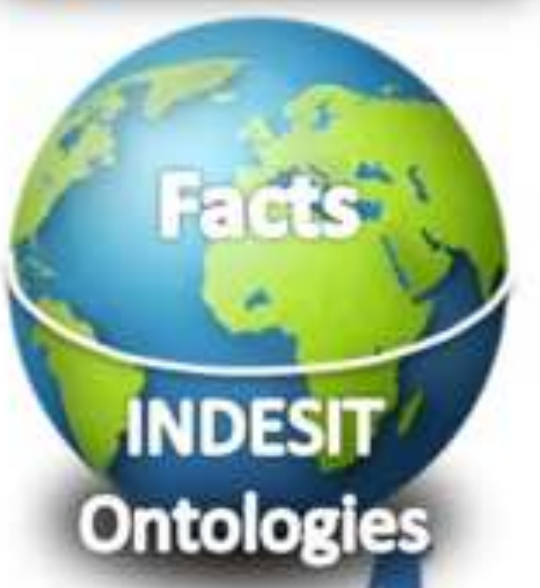
clrinks

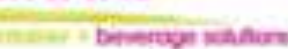

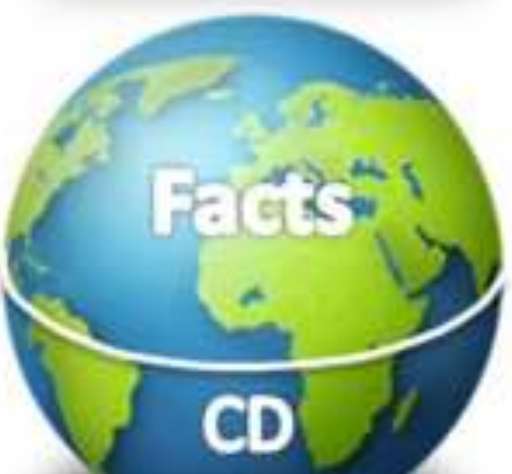

Ontologies

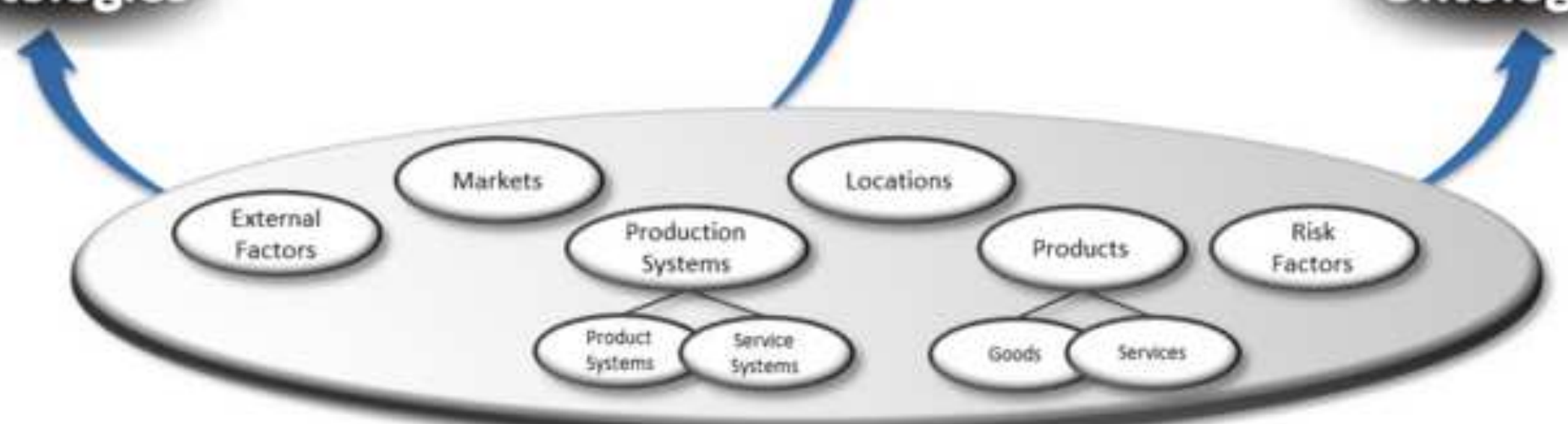

Product-Service Production Reference Ontologies 
Click here to download high resolution image

\begin{tabular}{|l|l|l|l|l|}
\hline Level 0 & CORE (ULO) & (Highfleet) \\
\hline Level 1 & & Systems \\
\hline Level 2 & & Designed Systems & Natural Systems \\
\hline Level 3 & Healthcare Systems & Manufacturing Business Systems & Banking Systems \\
\hline
\end{tabular}
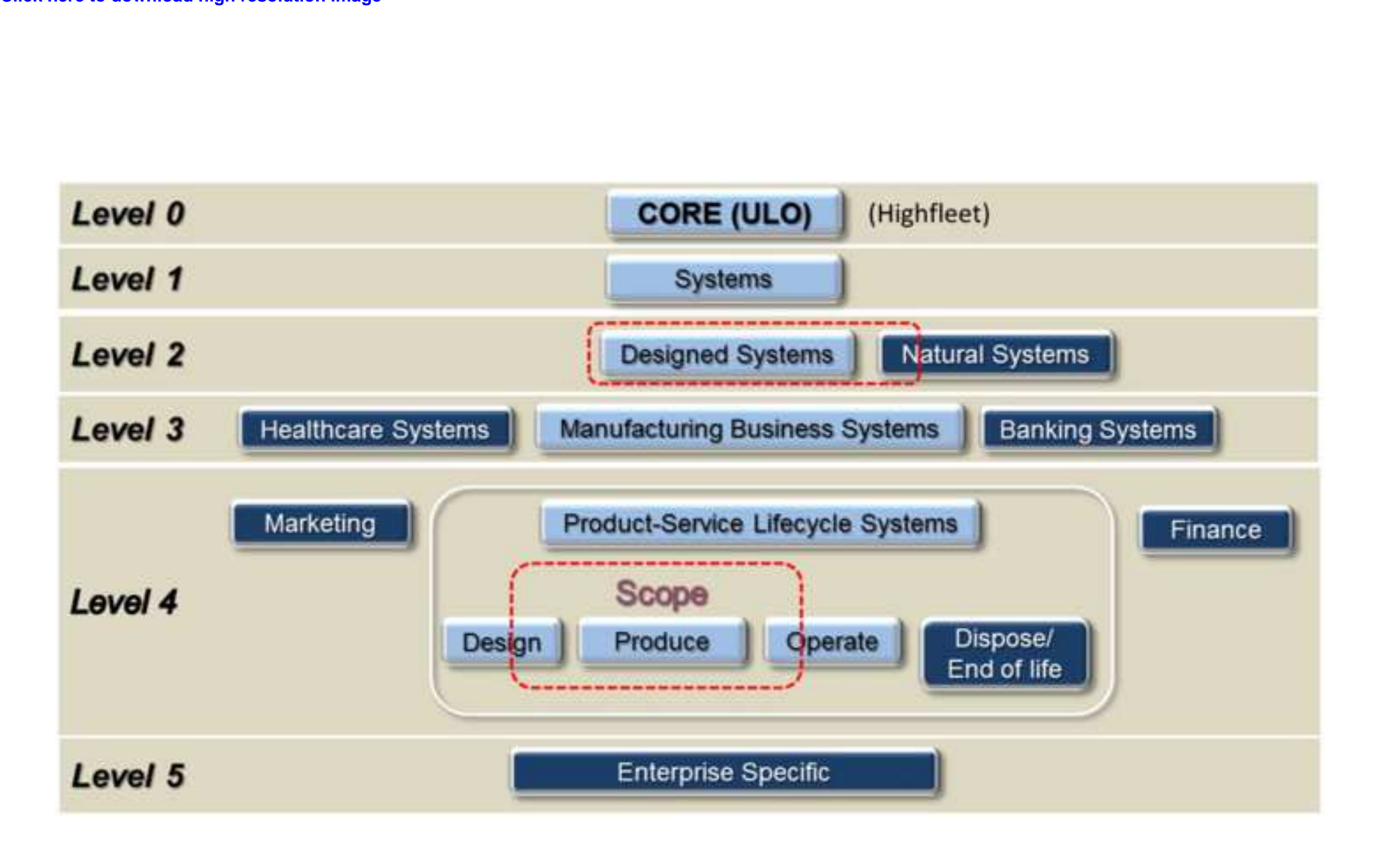
Click here to download high resolution image

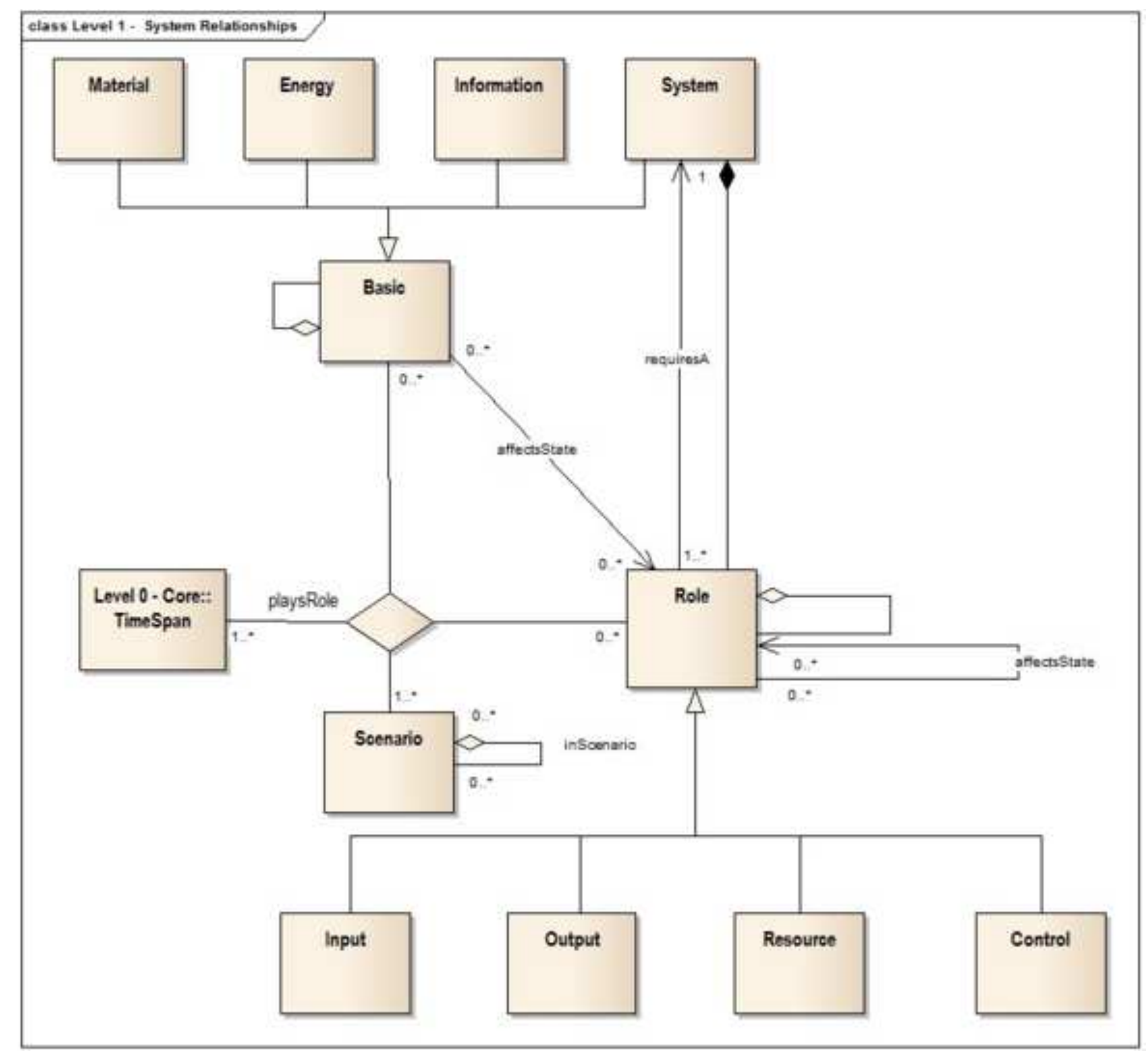


Click here to download high resolution image

:Name "1SYS - Context"

Use MLO

:Ctx 1SYSCtx

:Inst UserContext

\section{supCtx MLO}


:Prop Basic

:Inst Type

Inst NonLogicalFunctor

sup Particular

:partitionedBy (listof System Energy Material Information)

:rem "A Basic concept is independent of the <sym $>1$ SYSCtx.System $</$ sym $>$ or context, its definition does not depend on another concept.

A Basic can be classified as <sym $>1$ SYSCtx.System $</$ sym $>$, $<$ sym $>1$ SYSCtx. Information $</$ sym $>,<$ sym $>1$ SYSCtx.Material $</$ sym $>$ or $<$ sym $>1$ SYSCtx. Energy</sym $>$."

:referenceRem "2014 FLEXINET D3.1" 


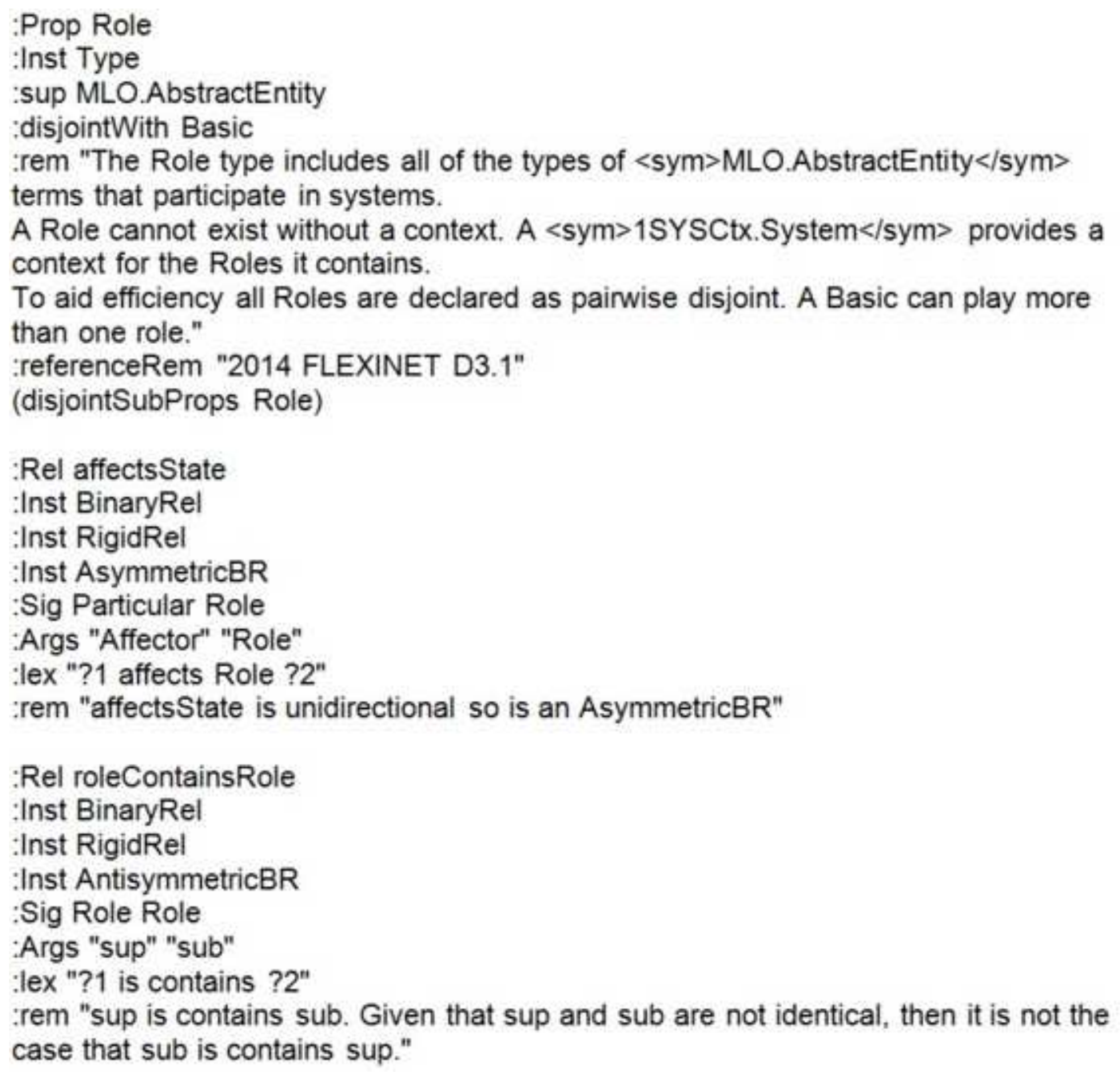


:Prop Scenario

Inst Type

sup AbstractEntity

:rem "A scenario provides a view upon a $<$ sym $>1$ SYSCtx. System $<$ /sym $>$ by providing an identifier for each $<$ sym $>1$ SYSCtx. Role $</$ sym $>$ played within the

\section{System." \\ :disjointWith Role \\ :disjointWith Basic}


:Rel playsRole :Inst TernaryRel

Inst NonRigidRel

Sig Basic Role Scenario

Args "Basic" "Role" "Scenario"

:lex "Basic entity ?1 plays Role ?2 in Scenario ?3"

:rem "To provide a $<$ sym $>$ RootCtx. TimeSpan $</$ sym $>$ use the ECLIF operator $<$ sym $>$ holds $\ln </$ sym $>$." 
$(=>$ (Role ?r)

(exists (?s)

(and (System ?s)

$$
\text { (requiresA ?r ?s)))) }
$$

:IC hard "The Role ?r requiresA System to provide a context." 
(=> (requiresA ?x ?y)

(systemContainsRole ?y ?x))

\#A Role requiring a System as a context implies that the System contains the Role 


\section{Control \& Orchestration}

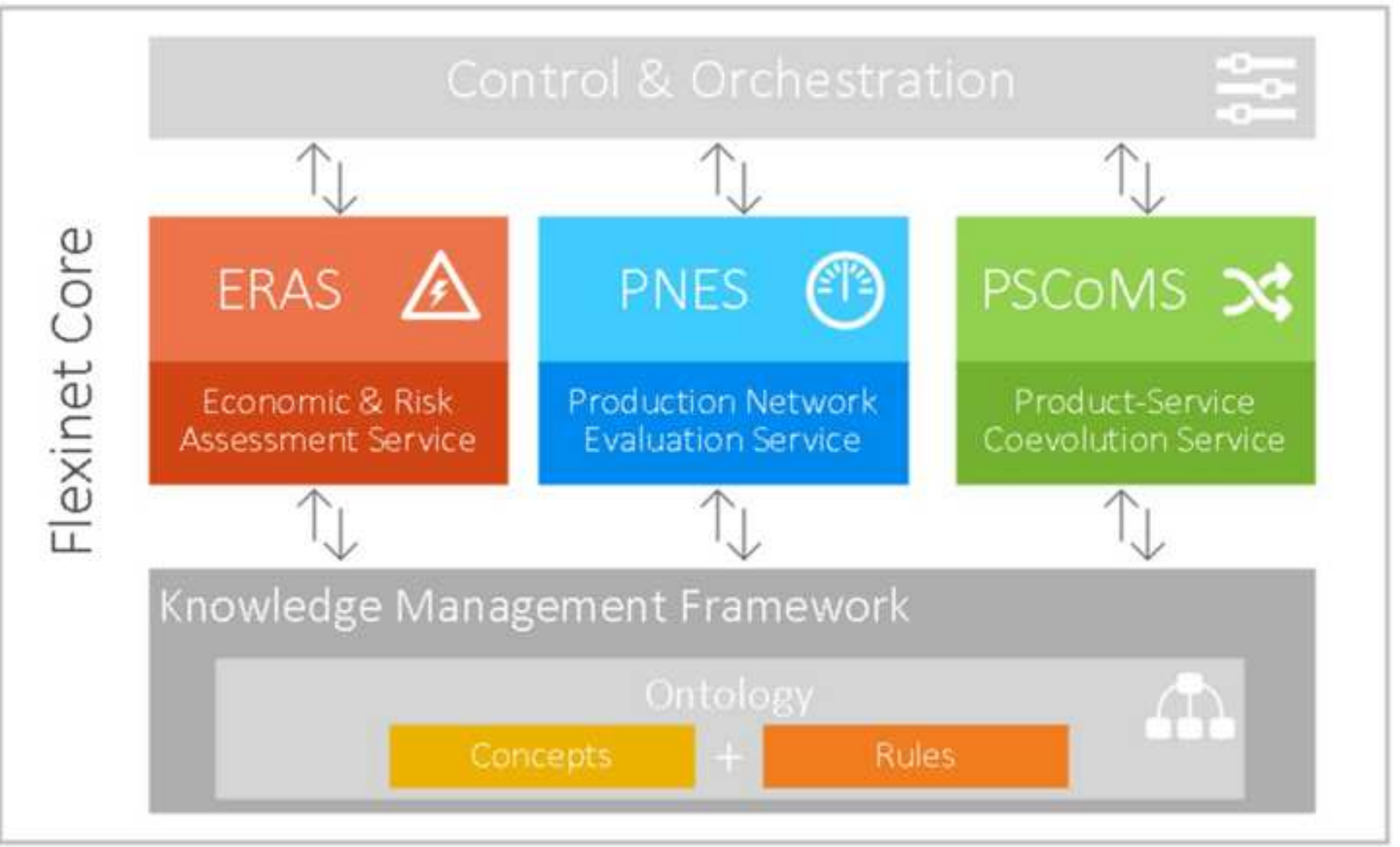


Click here to download high resolution image

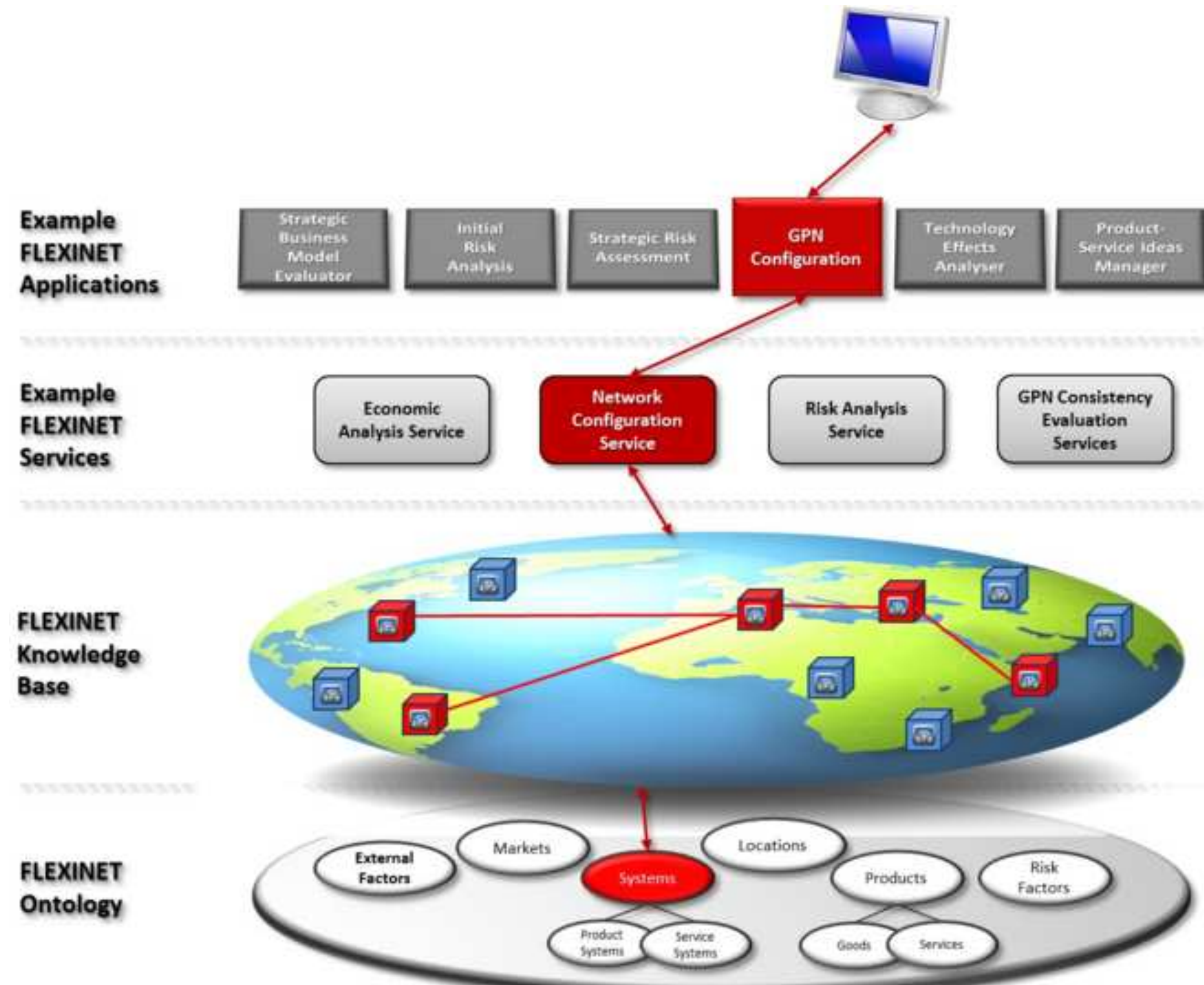

Example
FLEXINET
Application

FLEXINET

Services 
(and (Input ?input1)

(requiresA ?input1 ?gpn)

(Characteristic ?c01)

(characteristicRel ?c01 ?VT01 ?U01 ?v01)

(roleHasCharacteristic ?input1 ?c01)

(roleHasCharacteristic ?output1 ?c01)

(requiresA ?output1 ?f01)

(playsRoleActorInGPNS ?f01 BottleSupplier CD_GPN_Configurator)) 
Click here to download high resolution image

\begin{tabular}{|c|c|c|c|c|c|c|}
\hline 301 & 2001 & rrole1 & $P C O 1$ & PVTO1 & NoO1 & Not \\
\hline Co_fta'y & Copping & Outputcapoing & Volume & Fixed & «c & (RootCb. listof 33) \\
\hline$C D$ _ugo & Capping & OutputCapping & Volume & Fixed & $\propto$ & (RootCtx.listof 33) \\
\hline
\end{tabular}


Click here to download high resolution image

88 PNES

Production Network Evaluation Service

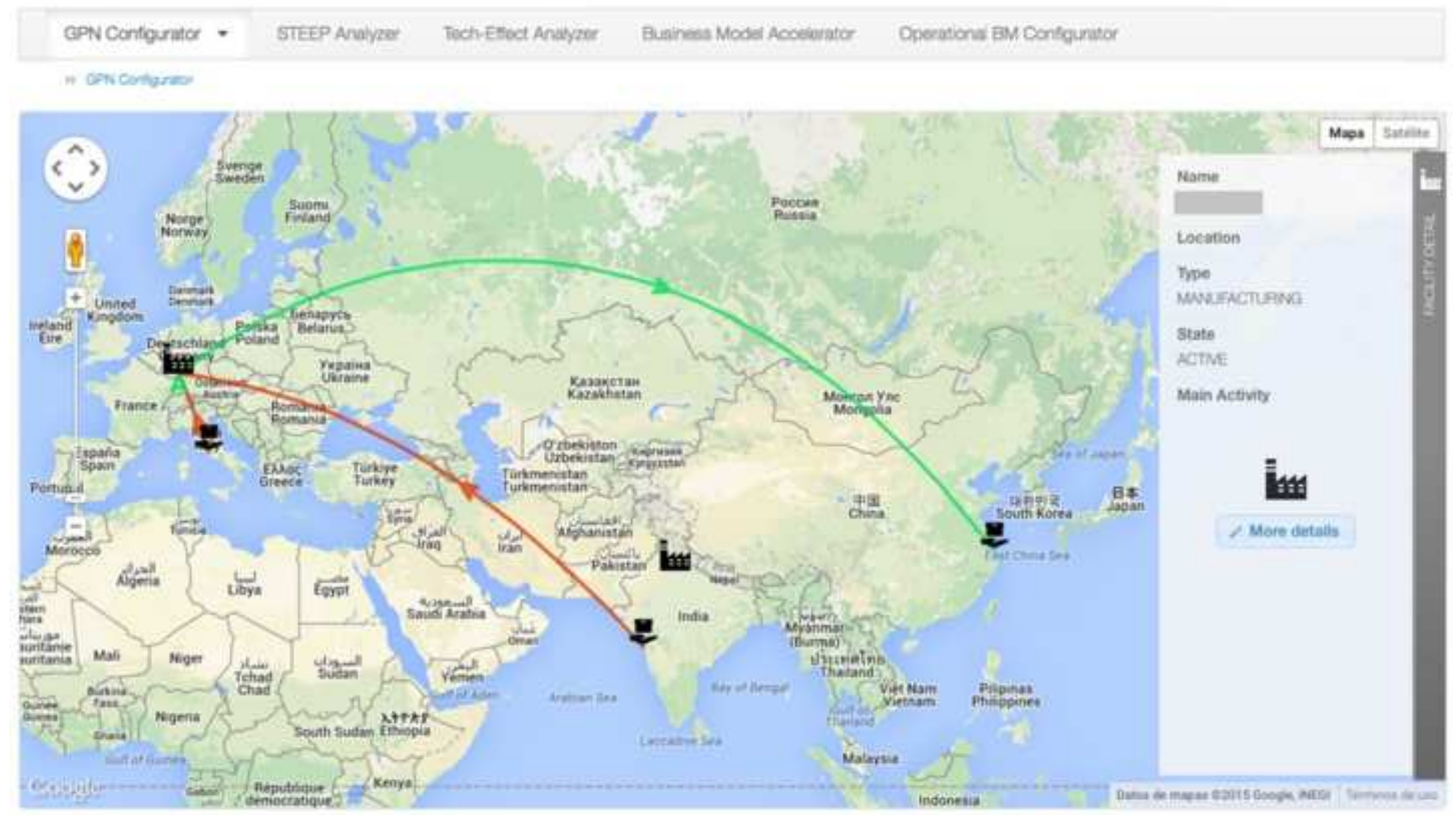

